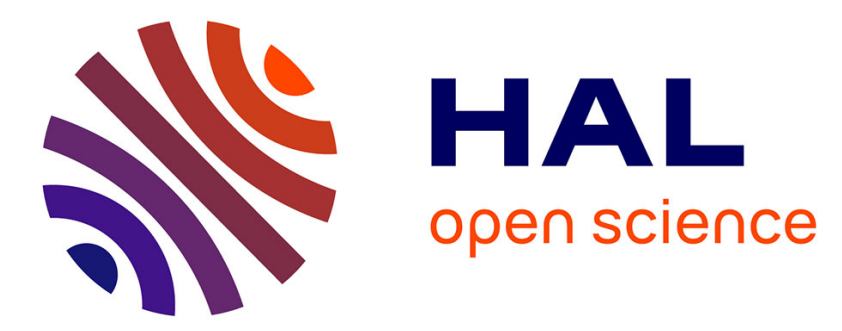

\title{
Cavezzo, the first Italian meteorite recovered by the PRISMA fireball network. Orbit, trajectory, and strewn-field
}

D Gardiol, D Barghini, A Buzzoni, A Carbognani, M Di Carlo, M Di Martino, C Knapic, E Londero, G Pratesi, S Rasetti, et al.

\section{To cite this version:}

D Gardiol, D Barghini, A Buzzoni, A Carbognani, M Di Carlo, et al.. Cavezzo, the first Italian meteorite recovered by the PRISMA fireball network. Orbit, trajectory, and strewn-field. Monthly Notices of the Royal Astronomical Society, 2020, 501 (1), pp.1215-1227. 10.1093/mnras/staa3646 . hal-03045589

\section{HAL Id: hal-03045589 \\ https://hal.science/hal-03045589}

Submitted on 9 Mar 2021

HAL is a multi-disciplinary open access archive for the deposit and dissemination of scientific research documents, whether they are published or not. The documents may come from teaching and research institutions in France or abroad, or from public or private research centers.
L'archive ouverte pluridisciplinaire HAL, est destinée au dépôt et à la diffusion de documents scientifiques de niveau recherche, publiés ou non, émanant des établissements d'enseignement et de recherche français ou étrangers, des laboratoires publics ou privés. 


\title{
Cavezzo, the first Italian meteorite recovered by the PRISMA fireball network. Orbit, trajectory, and strewn-field
}

\author{
D. Gardiol ${ }^{1 \star}$, D. Barghini ${ }^{1,2}$, A. Buzzoni ${ }^{3}$, A. Carbognani ${ }^{3}$, M. Di Carlo ${ }^{4}$, M. Di Martino ${ }^{1}$, C. Knapic ${ }^{5}$, \\ E. Londero ${ }^{5}$, G. Pratesi ${ }^{6,7}$, S. Rasetti ${ }^{1}$, W. Riva ${ }^{8}$, R. Salerno ${ }^{9}$, G. M. Stirpe ${ }^{3}$, G. B. Valsecchi ${ }^{7}, 10$, \\ C. A. Volpicelli ${ }^{1}$, S. Zorba ${ }^{5}$, F. Colas ${ }^{11,12}$, B. Zanda ${ }^{13,11,12}$, S. Bouley ${ }^{14,11,12}$, S. Jeanne ${ }^{11,12}$, \\ A. Malgoyre ${ }^{15,12}$, M. Birlan ${ }^{11,12}$, C. Blanpain ${ }^{15,12}$, J. Gattacceca ${ }^{16,12}$, J. Lecubin ${ }^{15,12}$, C. Marmo ${ }^{14}$, \\ J.L. Rault ${ }^{17,11,12}$, J. Vaubaillon ${ }^{11,12}$, P. Vernazza ${ }^{18,12}$, F. Affaticati ${ }^{19}$, M. Albani ${ }^{19}$, A. Andreis ${ }^{20}$,

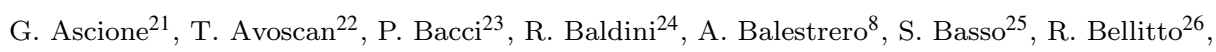 \\ M. Belluso ${ }^{27}$, C. Benna ${ }^{1}$, F. Bernardi ${ }^{28}$, M. E. Bertaina ${ }^{2}$, L. Betti ${ }^{29}$, R. Bonino ${ }^{2}$, K. Boros ${ }^{30}$, A. Bussi ${ }^{22}$, \\ C. Carli ${ }^{7}$, T. Carriero ${ }^{1}$, E. Cascone ${ }^{31}$, C. Cattaneo ${ }^{32}$, A. Cellino ${ }^{1}$, P. Colombetti ${ }^{2,33}$, E. Colombi ${ }^{34}$,
}

M. Costa $^{8}$, G. Cremonese ${ }^{35}$, D. Cricchio ${ }^{36}$, G. D'Agostino ${ }^{37}$, M. D'Elia ${ }^{38}$, M. De Maio ${ }^{39}$, P. Demaria ${ }^{20}$,

A. Di Dato ${ }^{31}$, R. Di Luca ${ }^{3}$, F. Federici ${ }^{40}$, V. Gagliarducci ${ }^{41}$, A. Gerardi ${ }^{41}$, G. Giuli ${ }^{42}$, D. Guidetti ${ }^{43}$,

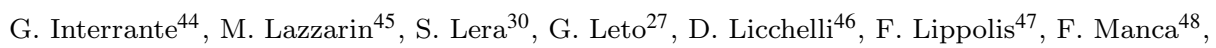

S. Mancuso ${ }^{1}$, F. Mannucci ${ }^{49}$, R. Masi ${ }^{50}$, S. Masiero ${ }^{36}$, S. Meucci ${ }^{50}$, A. Misiano ${ }^{37}$, V. Moggi Cecchi ${ }^{5}$

E. Molinari ${ }^{52}$, J. Monari ${ }^{43}$, M. Montemaggi ${ }^{26}$, M. Montesarchio ${ }^{53}$, G. Monti ${ }^{54}$, P. Morini ${ }^{55}$, A. Nastasi ${ }^{36}$,

E. Pace ${ }^{56}$, R. Pardini ${ }^{34}$, M. Pavone ${ }^{57}$, A. Pegoraro ${ }^{58}$, S. Pietronave ${ }^{54}$, T. Pisanu ${ }^{52}$, N. Pugno $^{59}$,

U. Repetti ${ }^{22}$, M. Rigoni ${ }^{32}$, N. Rizzi ${ }^{47}$, C. Romeni ${ }^{60}$, M. Romeo $^{37}$, S. Rubinetti ${ }^{61}$, P. Russo ${ }^{21}$, F. Salvati ${ }^{1}$,

D. Selvestrel ${ }^{35}$, R. Serra ${ }^{62}$, C. Simoncelli ${ }^{39}$, R. Smareglia ${ }^{5}$, M. Soldi ${ }^{32}$, R. Stanga 29 , F. Strafella ${ }^{38}$,

M. Suvieri ${ }^{63}$, C. Taricco ${ }^{2}$, G. Tigani Sava ${ }^{55}$, M. Tombelli ${ }^{44}$, P. Trivero ${ }^{64}$, G. Umbriaco ${ }^{45}$, R. Vairetti ${ }^{65}$,

G. Valente ${ }^{66}$, P. Volpini ${ }^{50}$, R. Zagarella ${ }^{67}$ and A. Zollo ${ }^{53}$

Affiliations are listed at the end of the paper

Accepted 2020 November 16. Received 2020 November 9; in original form 2020 September 18

\begin{abstract}
Two meteorite pieces have been recovered in Italy, near the town of Cavezzo (Modena), on $4^{\text {th }}$ January 2020. The associated fireball was observed on the evening of New Year's Day 2020 by eight all-sky cameras of the PRISMA fireball network, a partner of FRIPON. The computed trajectory had an inclination angle of approximately $68^{\circ}$ and a velocity at infinity of $12.8 \mathrm{~km} \mathrm{~s}^{-1}$. Together with the relatively low terminal height, estimated as $21.5 \mathrm{~km}$, those values were indicating the significant possibility of a meteorite dropping event, as additionally confirmed by the non zero residual total mass. The strewn-field was computed taking into account the presence of two bright light flashes, revealing that the meteoroid had been very likely subject to fragmentation. Three days after the event, two samples, weighing $3.1 \mathrm{~g}$ and $52.2 \mathrm{~g}$, were collected as a result of a dedicated field search and thanks to the involvement of the local people. The two pieces were immediately recognised as freshly fallen fragments of meteorite. The computed orbital elements, compared with the ones of known Near-Earth Asteroids from the NEODyS database, are compatible with one asteroid only; $2013 \mathrm{VC}_{10}$. The estimated original mass of the meteoroid, $3.5 \mathrm{~kg}$, and size, approximately 13 $\mathrm{cm}$, is so far the smallest among the current 35 cases in which meteorites were recovered from precise strewn-field computation thanks to observational data. This result demonstrates the effectiveness of accurate processing of fireball network data even on challenging events generated by small size meteoroids.
\end{abstract}

Key words: meteorites, meteors, meteoroids - methods: data analysis - techniques: image processing 


\section{INTRODUCTION}

The analysis of meteoritic material plays a relevant role in modern planetary sciences, since the fall of meteorites provides the easiest and cheapest way to gather extra-terrestrial samples. The mineralogy and petrology of these samples are the major sources of information about the geology, formation and evolution of minor and major bodies in the Solar System and beyond (e.g. Kruijer et al. 2020 and references therein). The scientific importance of such material is even higher if the interaction of the body with the Earth's atmosphere, generating the meteorite falls, is observed. Firstly, the observation of the meteor can provide crucial information about the physical properties of the body entering the atmosphere, which usually ablates for the most part before reaching the ground, if anything survives. In this case, the knowledge of the orbit of the meteoroid unveils its origin in the Solar System which can be linked with the physical and chemical characterisation of the meteorite itself. At this time of writing, the Meteoritical Database ${ }^{1}$ lists almost 64,000 officially classified meteorites. Among them, to the authors' knowledge, only 35 (plus at least 2 not yet published) were collected together with a sufficient set of observations of their atmospheric path, allowing a reliable reconstruction of their heliocentric orbit before the interaction with the Earth's atmosphere. Gathering sufficient statistics for meteoroid orbits would enable investigations into the possible link between different meteorite classes and their origin in the Solar System. Ultimately, the knowledge of the source regions of particular meteorite groups can provide constraints for the identification of a common parent body. As an example of recent relevant results on this topic, the reader can refer to Granvik \& Brown (2018), Jenniskens et al. (2019) and Unsalan et al. (2019). The importance of such results for planetary science is so pronounced that efforts even have been made to reconstruct meteorite pre-impact orbits from historical records (Gounelle et al. 2006).

The case of the Pribram meteorite in 1959 (Ceplecha 1961) represents the first successful meteorite recovery resulting from the observation of a bright meteor, which allowed for precise computation of its atmospheric trajectory, dynamics and dark flight. At the same time, this was the first meteorite recovery carried out thanks to a systematic meteors observation survey. Following the example of the Czechoslovakian Fireball Network, now European Fireball Network (Spurný et al. 2017b), many dedicated projects started to realise observational networks. Run by both amateur and professional astronomers, these networks have a shared goal of continuously monitoring the night-sky and detecting meteor and fireball events. The scientific outcome for this kind of survey is twofold; providing a unique tool to discover new meteor showers by focusing on the faint but predominant component of the detected events, and capturing the very rare occurrence of meteorite-dropping fireballs. In this context, one should highlight that only 20 among the 35 "pedigree" meteorites were collected as a result of dedicated

1 The Meteoritical Society, https://www.lpi.usra.edu/meteor/ observational surveys (see Tab. 1). Excluding the well-known but out-of-range events of Almahata Sitta and Chelyabinsk, the remaining 13 falls were documented through sporadic observations only, such as security cameras, dash cams and visual reports. For this reason, the past few years have witnessed a remarkable and ever increasing effort to extend the coverage of meteor networks worldwide and maximise the efficiency in the recovery of meteorites. As a result, 9 among the 20 meteorites collected, thanks to meteor surveillance networks, were recovered most recently between $2014-2020$.

In this international scenario, the PRISMA all-sky camera network (Gardiol et al. 2016, 2019) was born in 2016 to achieve a systematic surveillance of meteors and fireballs in the skies over the Italian territory. In fact, PRISMA stands for "Prima Rete Italiana per la Sorveglianza sistematica di Meteore e Atmosfera" (First Italian Network for Meteors and Atmosphere systematic Surveillance). At this time of writing, PRISMA has deployed 52 stations, among which 37 are fully operating and 15 are in installation phase. The PRISMA project is part of the international collaboration initiated by the FRIPON project (Fireball Recovery and InterPlanetary Observation Network, Colas et al. 2014, Jeanne et al. 2019 and Colas et al. 2020, submitted).

In this paper, we report on the finding of two meteorite pieces in Italy, near the Cavezzo village (Modena, EmiliaRomagna). The meteorite-dropping fireball, which reached a brightest absolute magnitude of -9.5 , was observed on the evening of New Year's Day 2020 by eight all-sky cameras of the PRISMA network. The two fragments, weighing $3.1 \mathrm{~g}$ and $52.2 \mathrm{~g}$ respectively, were collected as a result of a dedicated field search and thanks to the involvement of the local people. In Sect. 2, we illustrate the preliminary strewn-field computation and the meteorite search activity, and give a short description of the two recovered fragments. Section 3 gives a complete review of the fireball data analysis and its physical characterisation. In Sect. 4, we provide the orbital parameters and discuss a possible progenitor for the observed meteoroid. We draw our conclusions in Sect. 5 .

\section{THE FIREBALL EVENT}

\subsection{Preliminary trajectory and strewn-field}

On $1^{\text {st }}$ January at 18:26:53 UT eight stations of the PRISMA network detected a brilliant fireball, named IT20200101, in the skies of northern Italy (the list is shown in Tab. 2). The FRIPON automatic alert system performed a preliminary data reduction based on four cameras (ITPI03, ITTO02, ITER04, ITVE02). The remaining cameras were not configured to work as part of the automatic data reduction pipeline, having had being installed just prior to the detection. These preliminary results indicated a high probability of a meteorite-dropping fireball, as the computed preatmospheric velocity was found to be about $12 \mathrm{~km} \mathrm{~s}^{-1}$ and the inclination of the trajectory was high $\left(68^{\circ}\right)$. The meteor was tracked down to a height of about $22 \mathrm{~km}$, and the light curve showed two sudden brightenings at altitude of about $32 \mathrm{~km}$ and $30 \mathrm{~km}$. In order to get a preliminary estimate of the strewn-field, we reprocessed the data manually, adding two of the missing cameras (ITLO03 and ITER01). In the meantime, we also started to receive many reports 
Table 1. List and relevant data of "pedigree" meteorites, i.e., for which recovery was accompanied by a sufficient set of sporadic or systematic observations (optical, radio, infrasound, seismic, satellite), allowing for pre-impact orbit reconstruction. From left to right: name of the meteorite (approved by The Meteoritical Society), date of fall, preatmospheric velocity and mass, estimated terminal mass, meteorite total known weight (TKW) recovered on the ground, minimum absolute magnitude recorded, impact energy (equivalent tons of TNT, $1 \mathrm{~T}=4.187 \cdot 10^{9} \mathrm{~J}$ ), fireball network which provided the observations (if any) and references for table data. The uncertainties associated to the values of the table are not given here for simplicity, but can be found in the respective references.

\begin{tabular}{|c|c|c|c|c|c|c|c|c|c|}
\hline Name & Date UT & $\mathrm{v}_{\infty}\left[\mathrm{km} \mathrm{s}^{-1}\right]$ & $\mathrm{m}_{\infty}[\mathrm{kg}]$ & $\mathrm{m}_{\text {fin }}[\mathrm{kg}]$ & TKW $[\mathrm{kg}]$ & $\mathrm{M}^{\mathrm{a}}$ & $\mathrm{E}[\mathrm{T}]^{\mathrm{b}}$ & Fireball Network ${ }^{c}$ & $\operatorname{Ref}_{\Xi}^{3}$ \\
\hline PÅŹÃabram & $07 / 04 / 1959$ & 20.9 & 1300 & 80 & 5.6 & -19 & 70 & $\mathrm{CFN}$ & $1,2 \stackrel{\text { क्? }}{3}$ \\
\hline Lost City & $04 / 01 / 1970$ & 14.1 & 165 & 25 & 17 & -12 & 4 & PFN & 3,4, 紫 \\
\hline Innisfree & $06 / 02 / 1977$ & 14.7 & 42 & 4.9 & 4.58 & -12.1 & 1 & MORP & $5,6 \stackrel{\varrho}{\varrho}$ \\
\hline BeneÅąov & $07 / 05 / 1991$ & 21.3 & 4100 & $300^{\mathrm{d}}$ & 0.0116 & -19.5 & 200 & EFN & $5,7,8 \frac{\bar{M}}{\mathbb{3}}$ \\
\hline Peekskill & $09 / 10 / 1992$ & 14.7 & 5000 & - & 12.4 & -16 & 130 & - & 2,10 \\
\hline Tagish Lake & $18 / 01 / 2000$ & 15.8 & 56000 & 1300 & 10 & -22 & 1700 & - & 11,12 , 온 3 \\
\hline MorÃąvka & $06 / 05 / 2000$ & 22.5 & 1500 & 100 & 1.4 & -20 & 90 & & $14,15 \Omega^{2}$ \\
\hline Neuschwanstein & $06 / 04 / 2002$ & 20.9 & 300 & 20 & 6.22 & -17.2 & 16 & & 16,17, \\
\hline Park Forest & $27 / 03 / 2003$ & 19.5 & 11000 & - & 30 & -21.7 & 500 & & $19,2 \bar{\Theta}$ \\
\hline Villalbeto de la PeÃśa & $04 / 01 / 2004$ & 16.9 & 600 & 13 & 5.2 & -18 & 20 & & $21,22,23$ \\
\hline Bunburra Rockhole & $20 / 07 / 2007$ & 13.4 & 22 & 1.1 & 0.339 & -9.6 & 0.5 & DFN & $24,2 \frac{2}{2}$ \\
\hline Almahata Sitta & $07 / 10 / 2008$ & 12.4 & 40000 & 39 & 10.7 & -19.7 & 730 & 2 & $26,27,2 \underset{2}{2}, 29$ \\
\hline Buzzard Coulee & $21 / 11 / 2008$ & 18.0 & 10000 & - & $>200$ & -20 & 390 & - & 30,31 ,3्व2 2 \\
\hline Maribo & $17 / 01 / 2009$ & 28.3 & 2000 & $<20$ & 0.0258 & -20 & 190 & - & 33,3 象 \\
\hline Jesenice & 09/04/2009 & 13.8 & 170 & 20 & 3.611 & -15 & & SFN & 35,3 蔹. \\
\hline Grimsby & $26 / 09 / 2009$ & 20.9 & 30 & 5 & 0.215 & -14.8 & 2 & SOMN & $37 \frac{\mathrm{n}}{\mathrm{D}}$ \\
\hline KoÅąice & $28 / 02 / 2010$ & 15.0 & 3500 & 500 & 11.3 & -18 & 100 & - & 38,38 \\
\hline Mason Gully & $13 / 04 / 2010$ & 14.5 & 40 & - & 0.0245 & -9.4 & 1 & DFN & $40,4 \overline{\bar{I}}$ \\
\hline KriÅ¿evci & $04 / 02 / 2011$ & 18.2 & 50 & $<5^{\mathrm{e}}$ & 0.291 & -13.7 & 2 & $\mathrm{CMN}$ & $42 \stackrel{\circ}{\vec{\circ}}$ \\
\hline SutterâĂŹs Mill & $22 / 04 / 2012$ & 28.6 & 40000 & - & 0.943 & -19 & 4000 & - & $43 \stackrel{\circ}{\circ}$ \\
\hline Novato & $18 / 10 / 2012$ & 13.7 & 80 & - & 0.363 & -13.8 & 3 & CAMS & $44 \frac{\omega}{3}$ \\
\hline Chelyabinsk & $15 / 02 / 2013$ & 19.0 & $1.2 \cdot 10^{7}$ & 10000 & 730 & -27.3 & $5 \cdot 10^{5}$ & - & $45,46, \frac{\overrightarrow{1}}{2} 7$ \\
\hline Annama & $18 / 04 / 2014$ & 24.2 & 470 & 12.5 & 0.1679 & -18.3 & 30 & FFN & $48,49,30$ \\
\hline$\AA_{i d}$ d'Ãąr nad SÃązavou & $09 / 12 / 2014$ & 21.9 & 150 & ${ }^{f} \mathrm{f}$ & 0.087 & -15.3 & 9 & EFN & $51 \stackrel{0}{\frac{0}{0}}$ \\
\hline Porangaba & 09/01/2015 & - & - & & 0.970 & - & - & - & $52 \stackrel{\omega}{\omega}$ \\
\hline SariÃ ğiÃ ğek & $02 / 09 / 2015$ & 17.3 & 1700 & & 24.78 & -16.8 & 60 & - & 53 मे \\
\hline Creston & $23 / 10 / 2015$ & 16.0 & 50 & & 0.8523 & -12 & 2 & CAMS, SACN & 54 जु \\
\hline Murrili & $27 / 11 / 2015$ & 13.7 & 38 & & 1.68 & - & 0.9 & DFN & $55,5 \notin$ \\
\hline Ejby & $06 / 02 / 2016$ & 14.5 & 120 & & 8.982 & -14.0 & 3 & - & $57,5 \mathrm{G}$ \\
\hline Stubenberg & $06 / 03 / 2016$ & 14 & 600 & & 1.473 & -15.5 & 14 & EFN & $59,6 \mathbb{Z}$ \\
\hline Hradec KrÃąlovÃl' & $17 / 05 / 2016$ & - & & - & 0.134 & -11.5 & - & EFN & $61,6 \grave{2}$ \\
\hline DishchiiâĂŹbikoh & $02 / 06 / 2016$ & 16.6 & 100 & - & 0.07957 & -16 & 30 & CAMS, SACN & 63,6 喜. \\
\hline Dingle Dell & $31 / 10 / 2016$ & 15.4 & 40 & 1.4 & 1.150 & - & 1 & DFN & $65 \stackrel{\bigotimes}{\circ}$ \\
\hline Hamburg & $17 / 01 / 2018$ & 15.8 & 140 & $>1$ & $\sim 1$ & -16.3 & 5.5 & - & 66,6 送 \\
\hline Renchen & $10 / 07 / 2018$ & & $50^{\mathrm{h}}$ & - & 1.227 & -13.4 & 2 & EFN & 61,68 \\
\hline Cavezzo & $01 / 01 / 2020$ & 12.8 & 3.5 & 1.5 & 0.0553 & -9.5 & 0.07 & PRISMA & This wirk \\
\hline
\end{tabular}

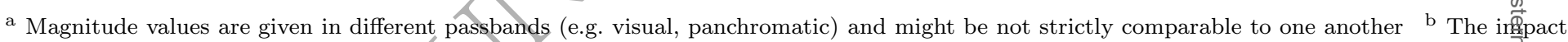
energy was calculated by the authors, if not provided in the original work, or updated to more precise estimates of preatmospheric mass aand/or velocity ${ }^{\mathrm{c}} \mathrm{CFN}=$ Czechoslovakian Fireball Network (now EFN), PFN = Prairie Fireball Network, MORP = Meteorite Observation and Reçzvery Project, EFN = European Fireball Network, DFN = Desert Fireball Network, SFN = Slovakian Fireball Network $($ part of EFN), SOMN $=$ Sou忽hern Ontario Meteor Network, CMN = Croatian Meteor Network (part of EFN), CAMS = Cameras for All-sky Meteor Surveillance, FFN = Fimnish Fireball Network, SACN = Spalding Allsky Camera Network, SkySentinel d Most of the terminal mass in gram-sized meteorites e Apart@ffrom the main mass, just a few $10-100 \mathrm{~g}$ meteorites are expected and $\sim 2000$ meteorites with mass $>1 \mathrm{~g}{ }^{\mathrm{f}}$ Main mass of $1.3 \mathrm{~kg}$ plus a second liagest meteorite in the range $100-200 \mathrm{~g}(\sim 250$ meteorites in the range $10-200 \mathrm{~g}, 6 \mathrm{~kg}$ total, and $\sim 3000$ meteorites of $0-1 \mathrm{~g}, 7 \mathrm{~kg}$ total $) \mathrm{g}$ Thereg is a disagreement between meteoroid size deduced from radiated energy from satellite observations $(\sim 15000 \mathrm{~kg})$ and cosmogenic radionuclide data $\left(\frac{+400-}{2}\right.$ $1800 \mathrm{~kg})^{\mathrm{h}}$ Computed by the authors considering a preatmospheric radius of $10-20 \mathrm{~cm}$ deduced from cosmogenic ${ }^{26} \mathrm{Al}$ data and a bulk density of $3.4 \mathrm{~g} \mathrm{~cm}^{-3}$ (reference 68), assuming a spherical shape.

References: [1] Ceplecha (1961) [2] Borovička \& Kalenda (2003) [3] McCrosky et al. (1971) [4] Ceplecha (1996) [5] Ceplecha \& Revelle (20.05) [6] Halliday et al. (1981) [7] Spurný (1994) [8] Borovička et al. (1998) [9] Spurný et al. (2014) [10] Brown et al. (1994) [11] Brown et al. (2900) [12] Brown et al. (2002) [13] Hildebrand et al. (2006) [14] Borovička et al. (2003a) [15] Borovička et al. (2003b) [16] Spurný et al. (2002)్ㅇ [17] Spurný et al. (2003) [18] Revelle et al. (2004) [19] Simon et al. (2004) [20] Brown et al. (2004) [21] Llorca et al. (2005) [22] Trigo-Rodríguez et al. (2006) [23] Bischoff et al. (2013) [24] Bland et al. (2009) [25] Spurný et al. (2012) [26] Jenniskens et al. (2009) [27] Borovička \& Charvát (2009) [28] Shaddad et al. (2010) [29] Welten et al. (2010) [30] Hildebrand et al. (2009) [31] Milley et al. (2010) [32] Wilson \& McCausland (2012) [33] Haack et al. (2012) [34] Borovička et al. (2019) [35] Spurný et al. (2010) [36] Bischoff et al. (2011) [37] Brown et al. (2011) [38] Borovička et al. (2013a) [39] Tóth et al. (2015) [40] Spurný et al. (2011) [41] Dyl et al. (2016) [42] Borovička et al. (2015) [43] Jenniskens et al. (2012) [44] Jenniskens et al. (2014) [45] Popova et al. (2013) [46] Borovička et al. (2013b) [47] Brown et al. (2013) [48] Trigo-Rodríguez et al. (2015) [49] Kohout et al. (2017) [50] Bouvier et al. (2017) [51] Spurný et al. (2020) [52] Ferus et al. (2020) [53] Unsalan et al. (2019) [54] Jenniskens et al. (2019) [55] Bland et al. (2016) [56] Sansom et al. (2020) [57] Spurný et al. (2017a) [58] Haack et al. (2019) [59] Spurný et al. (2016) [60] Bischoff et al. (2017) [61] Spurný et al. (2019) [62] Gattacceca et al. (2019) [63] Palotai et al. (2019) [64] Jenniskens et al. (2020) [65] Devillepoix et al. (2018) [66] Brown et al. (2019) [67] Gattacceca et al. (2020) [68] Bischoff et al. (2019) 
Table 2. PRISMA stations that observed the IT20200101 fireball. From left to right: station name, latitude, longitude and elevation above sea level.

\begin{tabular}{|c|c|c|c|}
\hline Station name & Lat. $\mathrm{N}\left[{ }^{\circ}\right]$ & Long. $\mathrm{E}\left[{ }^{\circ}\right]$ & El. $[\mathrm{m}]$ \\
\hline Bedonia (ITER04) & $44^{\circ} 30^{\prime} 27^{\prime \prime} 7$ & $09^{\circ} 37^{\prime} 57^{\prime \prime} 0$ & 550 \\
\hline Rovigo (ITVE02) & $45^{\circ} 04^{\prime} 54^{\prime \prime} 0$ & $11^{\circ} 47^{\prime} 42^{\prime \prime} \cdot 2$ & 15 \\
\hline Felizzano (ITPI03) & $44^{\circ} 54^{\prime} 45^{\prime \prime} 0$ & $08^{\circ} 26^{\prime} 14^{\prime \prime} 0$ & 114 \\
\hline Loiano (ITER01) & $44^{\circ} 15^{\prime} 23^{\prime \prime} 7$ & $11^{\circ} 19^{\prime} 54^{\prime \prime} 4$ & 787 \\
\hline Cecima (ITLO03) & $44^{\circ} 48^{\prime} 52^{\prime \prime} 7$ & $09^{\circ} 04^{\prime} 43^{\prime \prime} 6$ & 670 \\
\hline Navacchio (ITTO02) & $43^{\circ} 40^{\prime} 59^{\prime \prime} 5$ & $10^{\circ} 29^{\prime} 29^{\prime \prime} 9$ & 15 \\
\hline Padova (ITVE01) & $45^{\circ} 24^{\prime} 07^{\prime \prime} 0$ & $11^{\circ} 52^{\prime} 06^{\prime \prime} 7$ & 64 \\
\hline Asiago (ITVE03) & $45^{\circ} 50^{\prime} 57^{\prime \prime} 9$ & $11^{\circ} 34^{\prime} 06^{\prime \prime} 0$ & 1370 \\
\hline
\end{tabular}

from visual observers (52 observations reported through the PRISMA website on the International Meteor Organization online form ${ }^{2}$ ).

The high angle of fall resulted in an intense ablation process that led the fireball to shine with a mean absolute visual magnitude of about -7.5. The fireball disappeared from the camera images at an altitude of about $21.5 \mathrm{~km}$. According to the first computation of the strewn-field, made using a purely ablative model, we estimated a nominal impact point close to the village of Disvetro in the municipality of Cavezzo (province of Modena), near the local astronomical observatory, in the middle of the Po Valley. However, the light curve profile suggested that the object underwent a fragmentation process during the atmospheric flight, as also supported by eyewitnesses. Therefore, we expected meteorite pieces to be spread around the line joining Disvetro with the on-ground projection of the final part of the visible trajectory, near the village of Rovereto sulla Secchia.

\subsection{Meteorite search and recovery}

As soon as the preliminary strewn-field was identified (the day following the fall, i.e., $2^{\text {nd }}$ January in the early afternoon) we had to decide a strategy for the meteorite search. Within the PRISMA collaboration, a team of volunteers, both professionals and amateurs, is trained for meteorite hunting and dedicated to search activities. The strewn-field, located between the towns of Rovereto sulla Secchia and Disvetro, lies in a rural territory with many cultivated fields, groves and houses spread over the area. Since the vast majority of the terrain is private property, we notified the local authorities that teams of hunters would be there to search for meteorites on behalf of the PRISMA collaboration. To help searchers enter private terrains and areas, we also involved the Civil Protection of Cavezzo, as they are usually employed during public events, and their members are well known among the community. At the same time we prepared a press release to be published on the PRISMA website $^{3}$ and on the outreach platform of INAF (MediaINAF ${ }^{4}$ ). In the press release, we provided all the necessary information about the most probable area where fragments could be found and also a brief tutorial on how to recognise a freshly fallen meteorite. The goal of this strategy was to maximise

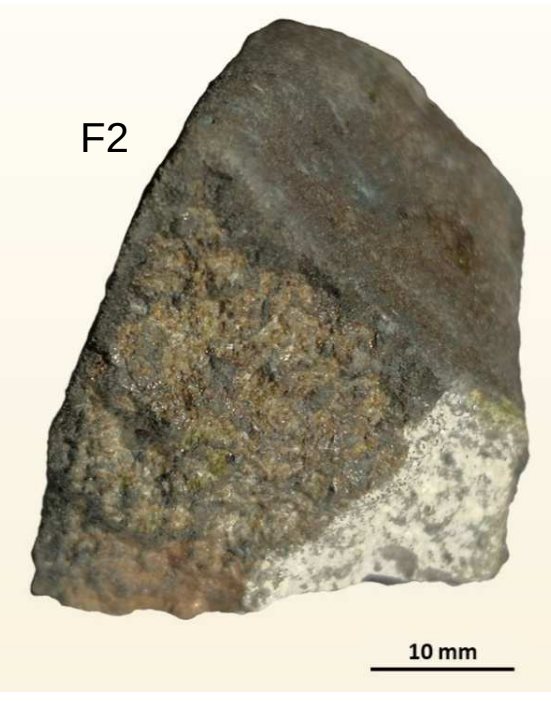

Figure 1. The two recovered samples of the Cavezzo meteorite. On the right, the first recovered fragment (F1, 3.1 g); on the left, the second and larger one (F2, $52.2 \mathrm{~g})$

the probability of a successful recovery by involving a larger number of people, even if not specially trained. The press release was also sent to local media in the Modena area, encouraging local inhabitants to start their own search or at least to be aware that they might chance upon meteorite fragments, and in this case to contact us by email. The news was made public on the late afternoon of $2^{\text {nd }}$ January, and already on $3^{\text {rd }}$ January we started receiving reports from people in the local area and giving interviews to local and national newspapers and televisions. By the morning of $4^{\text {th }}$ January, a team of about twenty hunters was ready to start searches on Sunday $5^{\text {th }}$, while a small scouting group from Bologna University led by Romano Serra was already onsite. On $4^{\text {th }}$ January at 3 PM local time we received an email with the first reliable meteorite candidate from Mr. Davide Gaddi, reporting the recovery of a small fragment (the size of a fingernail) on an embankment along the Secchia river. We immediately arranged a meeting with Romano Serra, where Mr. Gaddi showed also a second larger fragment, found in the meantime in the same place, the size of a walnut. Both fragments were recognised to be freshly fallen meteorites. It was less than three days since the fireball event.

In the following days, the search for other fragments carried out by teams organised by PRISMA and by other people did not lead to further findings, even though a refined strewn-field was available in the meantime ${ }^{5}$. Bad weather and muddy fields also limited the area accessible for the search. We planned to resume searches in Spring 2020 hoping for better weather and terrain conditions but, up until now, the COVID-19 pandemic outbreak did not allow us to organise further on-field activities.

3 http://www.prisma.inaf.it/index.php/2020/01/02/una-meteorite-in-emilia-romagna

4 https://www.media.inaf.it/2020/01/02/forse-e-caduta-una-meteorite-in-emilia-romagna 

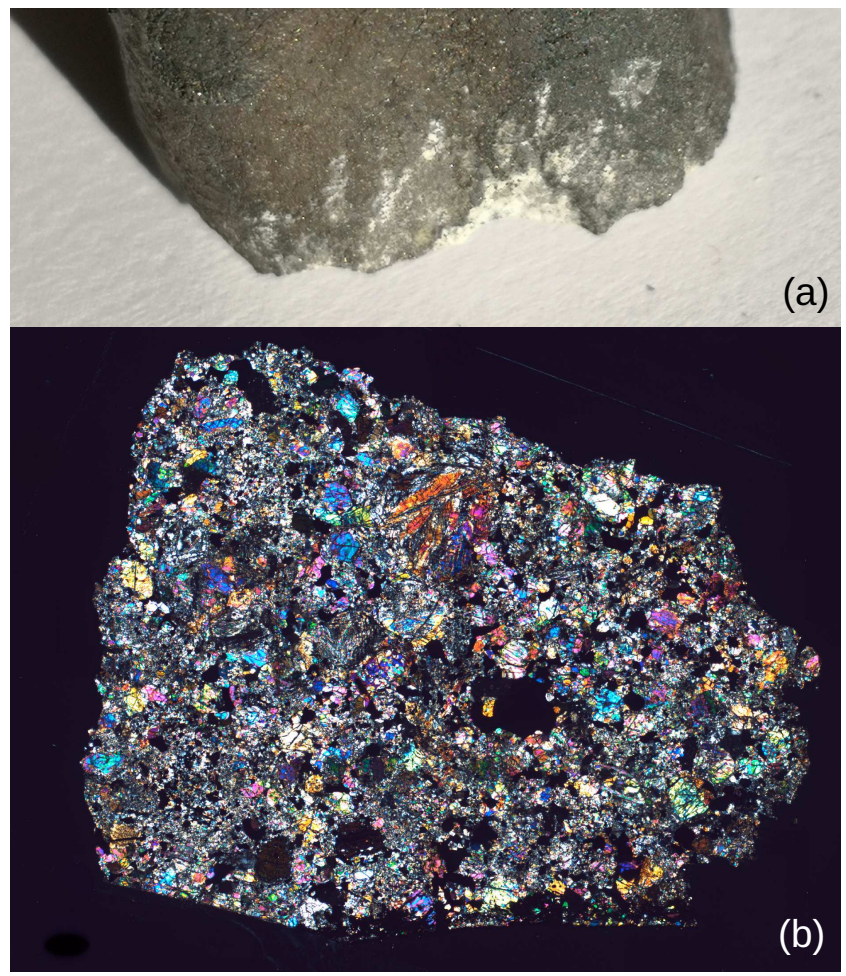

Figure 2. Details of the larger fragment F2 of the Cavezzo meteorite. (a) White streaks occur on one edge of F2, suggesting on-ground breakup of the original body; (b) photomosaic of polarising optical microscope images (transmitted light, crossed polars) of a thin sections obtained from F2 (field width $12 \mathrm{~mm}$ ) showing chondrules and chondrule fragments distributed in the matrix.

\subsection{Meteorite fragments description}

The two fragments were recovered at coordinates $44^{\circ} 49^{\prime} 43^{\prime \prime} .^{\prime} 7$ $\mathrm{N} 10^{\circ} 58^{\prime} 19^{\prime \prime} 5 \mathrm{E}$, at the border of a narrow country road that runs parallel to the left main embankment of the Secchia river. This is approximately halfway between Villa Motta and Rovereto sulla Secchia in the territory of the municipality of Cavezzo. Figure 1 shows the two finds. Fragment n.1 (F1), the first one to be found, has a tetrahedral form and weighs $3.1 \mathrm{~g}$. Fragment n.2 (F2), the largest one, weighs $52.2 \mathrm{~g}$. Both fragments clearly present a recently formed fusion crust on most of their surface. They also show what appears to be a light grey chondritic pattern on one of their sides, which was probably due to fragmentation that most likely occurred when they hit the ground. This interpretation is corroborated by the presence of an impact feature that is visible on one of the edges separating two of their sides, also accompanied by white streaks (Fig. 2a). In addition, F2 presents a darker grey colouration on one side, apparently a less pronounced secondary fusion crust, which is compatible with exposure due to a fragmentation event most probably associated to the brightening which occurred at a height of around $30 \mathrm{~km}$.

The meteorite fragments are currently being analysed at the Department for Earth Science of the Firenze Uni-

5 PRISMA and FRIPON teams independently computed two strewn-fields that are in close agreement with each other. versity for classification and study of the mineralogical, petrographic and geochemical characteristics. The result of this extensive analysis will be the subject of a dedicated article (Pratesi et al. 2020, submitted). However, as for fragment F2, it is worth mentioning that the composition of olivine and low-Ca pyroxene, the abundances of the mineral phases and the texture (Fig. 2b) are fully compatible with the $\mathrm{L}$ chondritic group. On the other hand, the modal mineralogy of fragment F1 (namely, the extremely low content of iron and troilite and the very high abundance of high-Ca pyroxene) is clearly different from the one typically found in L chondrites. On $5^{\text {th }}$ September 2020, the Nomenclature Committee of the Meteoritical Society has approved the classification proposal of "L5 anomalous" chondrite. Cavezzo is the only approved meteorite belonging to this class $^{6}$. Figure $2 \mathrm{~b}$ shows a photomosaic of polarising optical microscope images of a thin section obtained from F2, where, distributed in the matrix, chondrules and chondrule fragments can be observed.

The $\gamma$-ray activity measurement performed on the F2 sample at the INAF Monte dei Cappuccini Laboratory in Torino (Taricco et al. 2006, Colombetti et al. 2013) has shown the presence of many cosmogenic radioisotopes. Despite the small mass of F2 with respect to the samples that are commonly measured at this facility, the two characteristic lines of ${ }^{48} \mathrm{~V}$ at 983.53 and $1312.11 \mathrm{keV}^{7}$ are clearly visible, confirming beyond any doubt the presence of this radioisotope. Since ${ }^{48} \mathrm{~V}$ has a half-life of $15.97 \mathrm{~d}$, this is an indisputable proof of the very recent fall of the recovered meteorite, thus linking it again to the New Year's fireball. The results of the radiometric measures of F2 will be the subject of a forthcoming publication.

\section{FIREBALL DATA ANALYSIS}

PRISMA, as a partner of the FRIPON collaboration, currently shares the same technology of the network. Each station is equipped with a CCD camera $(6 \mathrm{~mm}$ diagonal, 1296 x 966 px), coupled with a short focal lens objective $(1.25 \mathrm{~mm})$, to obtain an all-sky field of view (FOV). The camera is connected to a Linux operating mini-PC via LAN and controlled by the open-source FREETURE software (Audureau et al. 2014). The camera is operated at $30 \mathrm{fps}$ (1/30 s exposure time) in order to sample the meteor trail with a suitable rate. The meteor detection is triggered locally in each node by a frame difference method, and cross-correlated with respect to data of other nodes to check for multiple detections of the same event. The $30 \mathrm{fps}$ video stream of the detected meteor is saved locally as FITS files and, in the case of a multiple detection, it is collected by the FRIPON central server, located at the Laboratoire d'Astrophysique de Marseille (LAM). Station monitoring, network security, software maintenance, real-time data processing and sharing tasks are in charge of FRIPON and LAM teams. PRISMA data are synchronised and stored at the IA2 (Italian Center for Astronomical Archives) INAF

\footnotetext{
6 https://www. lpi.usra.edu/meteor/metbull.php? code $=72534$

7 NUDAT database - https://www.nndc.bnl.gov/nudat2/
} 


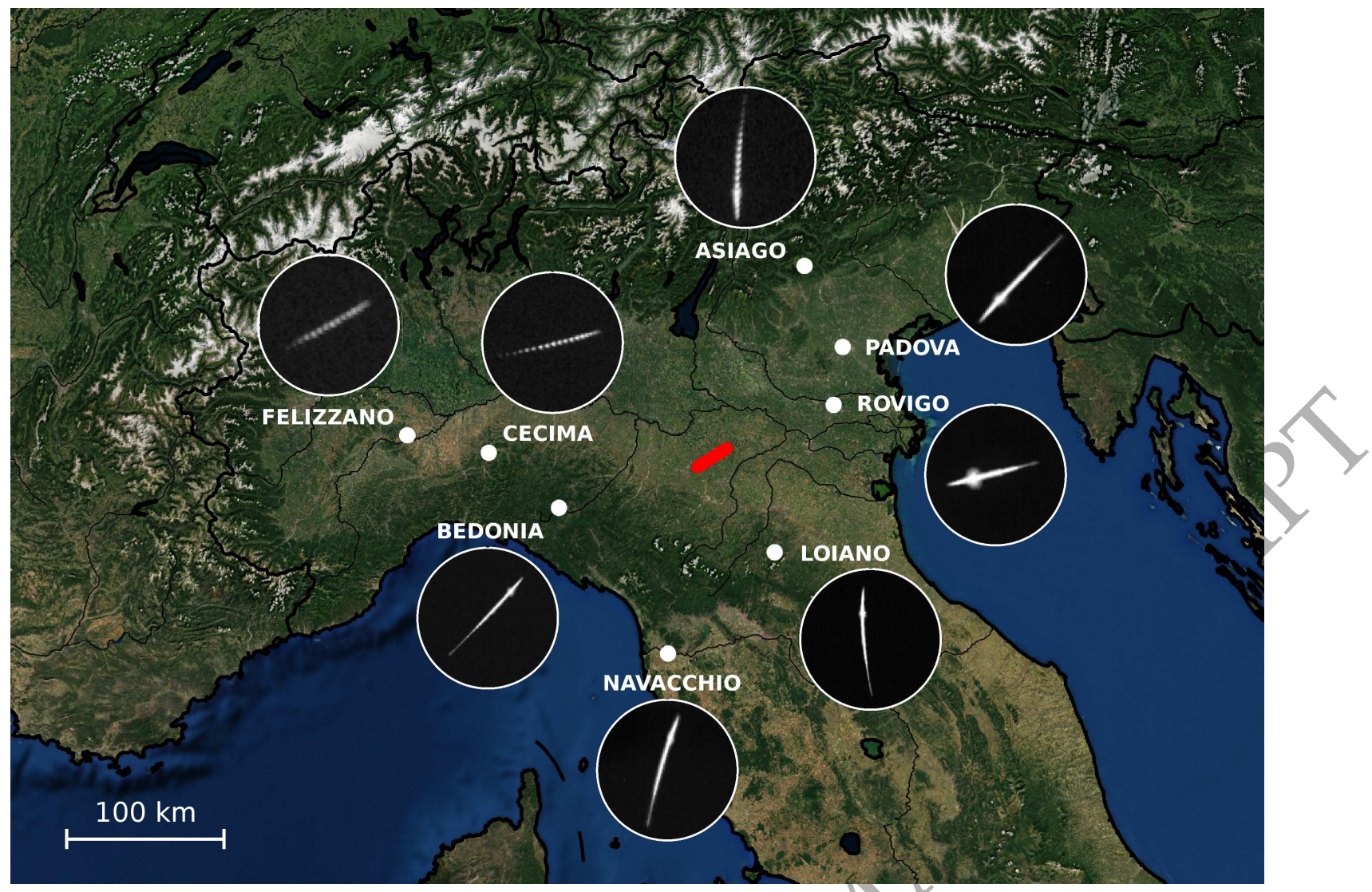

Figure 3. Map of the PRISMA stations (white dots) involved in the detection of the IT20200101 fireball. The red line plots the fireball bright trajectory projected on the ground, and white circles enclose the fireball trail seen by each camera (reconstructed from video records). Please notice that fireball trails are oriented accordingly to the specific in-situ hardware installation, and may be not strictly consistent with one another (all-sky images, from which meteor trails are cropped, were approximately oriented with $\mathrm{N}$ direction upward and E direction rightward). Background map was generated using the Matplotlib Basemap Toolkit (Hunter 2007, https://matplotlib.org/basemap/users/index.html)

archiving facilities in Trieste (Knapic et al. 2014). The PRISMA reduction pipeline is developed at the INAF Osservatorio Astrofisico di Torino and INAF - Osservatorio di Astrofisica e Scienze dello Spazio in Bologna. It is implemented in IDL $^{8}$ v8.7 and MATLAB ${ }^{9}$ Release $2015 \mathrm{~b}$.

The first step in the analysis of meteor detections is the astrometric and photometric reduction. Since almost no stars arise from the background noise in the $30 \mathrm{fps}$ video stream, the control software acquires a $5 \mathrm{~s}$ exposure image, named capture, every 10 minutes. With a limiting $\mathrm{V}$ magnitude of about +4.5 on this set of images, available for each operational night, hundreds of stars per frame are automatically identified and correlated with catalogue positions. They are then used as a reference for both astrometric and photometric calibration. Concerning astrometry, we implemented the approach introduced by Ceplecha (1987), Borovička (1990) and Borovička et al. (1995), in which the absolute astrometric solution of the camera is derived, in the alt/az system, as a function of

IDL - Interactive Data Language - Harris Geospatial Solutions, Inc. - https://www.harrisgeospatial.com/

9 MATLAB - Matrix Laboratory - MathWorks, Inc., http://www . mathworks.com
8 parameters. This analytical description accounts for the major distortion factors that are, in the case of PRISMA all-sky cameras, the pronounced radial distortion of the fish-eye lens and the possible mismatch of the optical centre with respect to the local zenith direction. Two additional parameters are introduced if the optical plate is found to be misaligned with respect to the local horizon plane. With respect to Borovička et al. (1995), we provided a new explicit parametrisation of the astrometric model, which reduces the parameters' correlation degree and improves overall convergence properties for the determination of the astrometric solution (Barghini et al. 2019a). At the same time, the photometric calibration is determined on the same set of images as well. Since no filter is applied over the lens, a wide passband magnitude is considered, roughly between 400 and $800 \mathrm{~nm}$, on the basis of the quantum efficiency of the camera and the transmission of the glass dome. This panchromatic magnitude is numerically computed from the catalogue UBVRI Johnson-Cousins system and therefore used to derive the zero-point and atmospheric extinction coefficient for each capture. For PRISMA cameras, we also determined and accounted for the efficiency loss along the radial direction that turns out to be of about 40 per cent from the centre to the very edge of the camera (Barghini et al. 2019b). 
We used the method outlined in Carbognani et al. (2020) to estimate the fireball atmospheric trajectory, its main physical parameters, and the best kinematic parameters in the terminal point of the luminous path. The atmospheric trajectory computation is performed according to the classical formulation reported in Ceplecha (1987) and Borovička (1990). The parameters of the dynamical model are derived based on the description given by Kalenichenko (2006) and references therein. In our case, however, the meteoroid has been most probably subject to fragmentation phenomena, so that the physical quantities are to be taken with caution. For the dark flight and strewn-field determination, Ceplecha (1987) formulation is again used, by computing the expected impact points in a range of mass-section ratios. The orbital parameters are derived both in an analytical way and by numerical integration, as the two methods have proven to provide consistent results (Clark \& Wiegert 2011).

\subsection{Astrometry and photometry}

Figure 3 shows the map of PRISMA stations that detected the IT20200101 fireball (white dots) together with the onground projection of the reconstructed trajectory (red line) and the images of the meteor trail seen by each camera (enclosed in white circles) obtained through the analysis of video records. The distance between the eight stations and the fireball atmospheric trajectory spans between 75 and $200 \mathrm{~km}$. While some cameras captured the bright flight in the central area of the FOV, other cameras recorded the fireball at a quite low elevation above the horizon. In particular, the astrometric reduction for data of two cameras (Felizzano and Cecima) results in elevations lower than $10^{\circ}$ for the final 5-10 points of the trajectory. Unfortunately, sky quality condition is not optimal in many PRISMA observational sites, due to light pollution which is especially severe in the Po valley. These experimental constraints prevent us from detecting stars, below $10^{\circ}$ of elevation for most PRISMA cameras, even in long-exposure calibration images. While residual systematic effects are numerically addressed (Barghini et al. 2019b), this correction can be only tentative below $10^{\circ}$ of elevation and the positional accuracy for these last points is questionable. To assess the potential effect of this bias over the final result, we first excluded these points and verified that the overall results (i.e., the trajectory computation) were unchanged within the measurement errors. In fact, their total weights are not predominant over other reference points, at the same timing, from the remaining six cameras. We finally included them since they provide important photometric data for the trailing edge of the fireball light curve.

The photometric analysis highlights that the fireball point spread function (PSF) saturated, in almost all cameras, between $2 \mathrm{~s}$ and $4.7 \mathrm{~s}$ from the beginning of the bright flight Barghini et al. (2019b) give a comprehensive analysis of the effects of PSF saturation for PRISMA cameras concluding that the astrometric precision is not significantly degraded at least below $h \leq 4$, where $h$ is the relative ratio of the PSF height to the saturation value, namely 4095 ADU (analog-to-digital units) for PRISMA 12-bit video records. To account for count loss on the saturated portion of the
Table 3. IT20200101 fireball parameters obtained from triangulation and dynamical model. The two columns refer to values at the beginning and end of the bright flight respectively (when applicable). Values of mass and diameter are computed from the mass-section ratio $D$ (in the hypothesis of pure ablation) by assuming a spherical shape of the meteoroid and for the measured meteorite bulk density of $3.322 \mathrm{~g} \mathrm{~cm}^{-3}$.

\begin{tabular}{|c|c|c|c|}
\hline & & Beginning & Terminal \\
\hline Time (UT) & $t$ & $18: 26: 52.9$ & $18: 26: 58.5$ \\
\hline Height $[\mathrm{km}]$ & $h$ & $75.9 \pm 0.2$ & $21.5 \pm 0.1$ \\
\hline Latitude $(\mathrm{N})$ & $\phi$ & $44^{\circ} 44^{\prime} 03^{\prime \prime} \pm 7^{\prime \prime}$ & $44^{\circ} 50^{\prime} 24^{\prime \prime} \pm 7^{\prime \prime}$ \\
\hline Longitude (E) & $\lambda$ & $10^{\circ} 43^{\prime} 09^{\prime \prime} \pm 7^{\prime \prime}$ & $10^{\circ} 57^{\prime} 25^{\prime \prime} \pm 7^{\prime \prime}$ \\
\hline Velocity $\left[\mathrm{km} \mathrm{s}^{-1}\right]$ & $v$ & $12.2 \pm 0.2$ & $4.0 \pm 0.2$ \\
\hline Mass-section ratio $\left[\mathrm{kg} \mathrm{m}^{-2}\right]$ & $D$ & $280 \pm 20$ & $210 \pm 20$ \\
\hline Mass $[\mathrm{kg}]$ & $m$ & $3.5 \pm 0.8$ & $1.5 \pm 0.4$ \\
\hline Diameter $[\mathrm{m}]$ & $d$ & $0.13 \pm 0.01$ & \\
\hline Luminous path length $[\mathrm{km}]$ & $L$ & 59 & \\
\hline Duration [s] & $T$ & 5.6 & \\
\hline Trajectory inclination $\left[{ }^{\circ}\right]$ & $T_{i}$ & $68.4 \pm 0.3$ & \\
\hline Trajectory azimuth $\left[{ }^{\circ}\right]^{2}$ & $a z$ & $238.1 \pm 0.2$ & \\
\hline Min. absolute magnitude & $M$ & $-9.5 \pm 0.5 @$ & $\mathrm{~m}$ \\
\hline Pre-atmospheric velocity $\left[\mathrm{km} \mathrm{s}^{-1}\right]$ & $v_{\infty}$ & $12.8 \pm 0.2$ & \\
\hline Ablation coefficient $\left[\mathrm{s}^{2} \mathrm{~km}^{-2}\right]$ & & $0.012 \pm 0.003$ & \\
\hline Max. dynamic pressure $[\mathrm{MPa}]$ & $P_{\max }$ & $1.0 \pm 0.3 @ 28$. & $\mathrm{km}$ \\
\hline Impact Energy [T TNT] & $E$ & $0.07 \pm 0.02$ & \\
\hline
\end{tabular}

PSF, a tentative correction is applied by fitting a bidimensional gaussian model to non-saturated pixels of the PSF. This analysis therefore aims to estimate the original PSF shape and unveils $h$ values that are mostly below 2 (and always below 4), also for the two bright flares (Sect. 3.2). These conclusions are confirmed by a visual inspection of the saturated portion of the PSF, which is confined to few pixels in its very centre for most part of the trajectory. From this approach, a saturation correction factor is therefore estimated and applied to results obtained through aperture photometry. The computed count loss fraction for the saturated portion of the bright flight is mostly confined under 30 per cent and raises up to about 50 per cent in correspondence of the brightest flare.

\subsection{Atmospheric trajectory and dynamical model}

The results of the atmospheric trajectory and dynamical model computation are summarised in Tab. 3 and Fig. 4. In particular, Fig. 4a shows the height of the fireball above the ground as a function of time since the beginning of the luminous path. The observed fireball trajectory begins at a starting height $h_{b}=75.9 \pm 0.2 \mathrm{~km}$ and ends up at a terminal height $h_{t}=21.5 \pm 0.1 \mathrm{~km}$. The total length of the luminous atmospheric path is approximately $59 \mathrm{~km}$, which was covered in about $5.6 \mathrm{~s}$. The meteoroid followed an atmospheric trajectory inclined by an angle of $68^{\circ} .4 \pm 0.3$ with respect to the horizontal plane, with an azimuth of $238^{\circ} .1 \pm 0^{\circ} .2$, travelling from WSW to ENE, and rapidly entered into the denser layers of the atmosphere. The height residuals of observed points with respect to the computed trajectory are plotted in Fig. $4 \mathrm{~b}$. The standard deviation of $\sigma_{h}=0.25 \mathrm{~km}$, considering the distance of the fireball to the observing stations, corresponds to angles less then $10^{\prime}$ and it is therefore always below the pixel resolution of our cameras. Systematic patterns are visible along the trajectory. Above $50 \mathrm{~km}$ of altitude, the descent of the body into the atmosphere is slower in comparison to the fitted trajectory. Furthermore, after the two flare events, an increased spreading of the height residuals 
is evident. Systematic effects associated to specific cameras may be related to PSF asymmetries that affect most part of the trajectory.

The observed velocity (Fig. 4c) allowed us to derive an entering speed of $12.2 \pm 0.2 \mathrm{~km} \mathrm{~s}^{-1}$ at $76 \mathrm{~km}$ of altitude. This speed started to decrease only in the denser layers of the atmosphere below $30 \mathrm{~km}$, just after the brightenings, where it lowered to $10 \mathrm{~km} \mathrm{~s}^{-1}$. At the end of the luminous path, $21.5 \mathrm{~km}$ above the ground, the meteoroid slowed down to $4.0 \pm 0.2 \mathrm{~km} \mathrm{~s}^{-1}$. The estimated value of $76 \mathrm{~km}$ for the beginning height of the observed trajectory is in close agreement with experimental and simulated data presented in Vida et al. (2018) for fireballs of asteroidal origin with a low entry speed $\left(<13 \mathrm{~km} \mathrm{~s}^{-1}\right)$, as seen by low sensitivity all-sky systems. They also found that low velocity meteors decelerate significantly prior to detection of the visible meteor trail. This is the case also for the Cavezzo bolide, for which we estimate a difference between $v_{\infty}$ and the entry speed of $0.6 \pm 0.3 \mathrm{~km} \mathrm{~s}^{-1}$.

The absolute magnitude light curve is shown in Fig. 4e. In the first two seconds, the brightness grew rapidly, reaching a plateau of about $M=-7.5$ between $t=2.0 \mathrm{~s}$ and $4.7 \mathrm{~s}$, followed by a sudden fading in the last second. Two rapid flares are visible at $3.95 \mathrm{~s}$ and $4.15 \mathrm{~s}$ with absolute magnitudes close to -9.5 and -8.5 , respectively, related to the already mentioned fragmentation. The corresponding altitudes are about $32.6 \mathrm{~km}$ and $30.7 \mathrm{~km}$, respectively, when the meteoroid was still moving at a speed of about $10.1 \mathrm{~km} \mathrm{~s}^{-1}$. Meteoroid fragmentation models usually assume that the fragmentation process starts when the aerodynamic pressure is equal to the mechanical strength $S$. According to the meteoroid height $h$ and speed $V$ in the main explosion (Foschini 1999), we can estimate a strength of about:

$S=\frac{\gamma-1}{\gamma} \rho_{s l} V^{2} e^{-h / H} \simeq 0.88 \mathrm{MPa}$,

where $\gamma \sim 1.7$ is the ratio of specific heats, $H \simeq 8 \mathrm{~km}$ is the atmospheric scale height and $\rho_{s l} \simeq 1.22 \mathrm{~kg} \mathrm{~m}^{-3}$ is the atmospheric density at sea level. This value is close to the maximum aerodynamic pressure that is attained at a height of about $28.2 \mathrm{~km}$ (see Fig. 4d). Since Cavezzo is a stony meteorite, a strength of about $10 \mathrm{MPa}$ could be expected, that is, about one order of magnitude greater. However, it is common to observe fragmentations at aerodynamic pressure well below $1 \mathrm{MPa}$ and even down to few tens of $\mathrm{kPa}$ (for example, see Popova et al. 2011, Devillepoix et al. 2019). This evidence suggests a particular weakness of the meteoroid which may be caused, for instance, by fractures already present when it was entering the atmosphere or by porosity of the material.

We estimated the density of the F2 sample by an accurate and precise 3D scanning of the outer surface (Pratesi et al. 2020, submitted). Given the measured density of $3.322 \mathrm{~g} \mathrm{~cm}^{-3}$ and by assuming a spherical shape for the entering meteoroid, the computed value for the masssection ratio $D$ derived by the dynamical model provides, in a purely ablative regime, an estimate of the mass and size before and after the luminous atmospheric transit. The meteoroid pre-atmospheric mass can be estimated to be 3.5 $\pm 0.8 \mathrm{~kg}\left(D=280 \pm 20 \mathrm{~kg} \mathrm{~m}^{-2}\right)$ with a diameter of $0.13 \pm$ $0.01 \mathrm{~m}$, while the final mass is $1.5 \pm 0.4 \mathrm{~kg}(D=210 \pm 20$ $\left.\mathrm{kg} \mathrm{m}^{-2}\right)$. Since there is evidence of possible fragmentation only at a height of about $30 \mathrm{~km}$, we consider our estimation of the initial mass as reliable. On the contrary, the value of the final mass is questionable. Apart from this, the relatively low ablated mass ratio of about 57 per cent could be attributable also to the very low pre-atmospheric speed of $12.8 \pm 0.2 \mathrm{~km} \mathrm{~s}^{-1}$ and to the steep inclination of the trajectory. Compared to the values given in Tab. 1, the preatmospheric mass for the Cavezzo meteorite is the lowest ever reported between "pedigree" meteorites. From the preatmospheric mass and velocity estimates, the impact energy results to be $0.07 \pm 0.02 \mathrm{~T} \mathrm{TNT}$, which is also the lowest among values given in Tab. 1.

\subsection{Atmospheric data}

The knowledge of the atmospheric conditions plays a key role in the computation of the dark flight and strewn-field of meteorite fragments that could be possibly found on the ground. In particular, the wind direction and intensity are the major drivers for the loss of accuracy of these predictions. This effect is even more important in our case, given the small residual mass after ablation and the even smaller expected mass and size of the fragments (order of $100 \mathrm{~g} / 1$ $\mathrm{cm})$. For these reasons, we specifically computed the atmospheric state for the Cavezzo area at the time of fall.

Meteorological data came from IOIS (Integrated Observations Ingesting System) elaborated and used at Meteo Expert, a private organisation providing meteorological services where weather models are internally developed and applied. All available data, coming from surface, upper air and remote sensing measurements, are integrated to produce initialisation to be perturbed for a limited-area ensemble prediction system. A variational quality control is applied to check data consistency (Steinacker et al. 2011, Tavolato \& Isaksen 2015); the observation is compared with the background and surrounding observations to determine its analysis weight in the system. This procedure is applied to develop perturbed initial data for usual forecast model, that runs at 00, 06, 12 and 18 UTC. However, in our case, as for several other applications including nowcasting, a hourly $3 \mathrm{D}$ grid is needed. This grid follows the modelâĂ tal mesh size at $3.5 \mathrm{~km}$, while in the vertical direction fifty variable-depth levels are used from surface to stratosphere. The scaling of weather parameters at a defined location is made by interpolating values from surrounding grid points, with a correction algorithm which takes into account subgrid terrain characteristics and local gradients.

\subsection{Dark flight and strewn-field}

Figure 5 shows the wind intensity and direction values at 18 UTC in the Cavezzo area as a function of the altitude. The wind was particularly intense at about $22 \mathrm{~km}$, which is the last observed point of the luminous path, reaching a speed of about $28 \mathrm{~m} \mathrm{~s}^{-1}$, and blowing at $45^{\circ}$ clockwise with respect to the meteoroid motion direction. The wind intensity decreases to reach a speed of about $20 \mathrm{~m} \mathrm{~s}^{-1}$ at $20 \mathrm{~km}$ altitude, and is confined below $10 \mathrm{~m} \mathrm{~s}^{-1}$ from $13 \mathrm{~km}$ downwards. This led to a significant shift of the strewn-field compared to a situation with zero wind, especially in the transverse direction. 
Table 4. Data regarding the nominal impact points with different $D$ final values. From top to bottom: final mass-section value, latitude and longitude of the impact point, shift parallel $(L)$ and orthogonal $(X)$ to motion direction of the bright flight and on-ground impact velocity.

\begin{tabular}{|c|c|c|c|c|c|c|c|c|c|c|c|}
\hline Quantity & & & & & & & & & & & \\
\hline Final $D\left[\mathrm{~kg} \mathrm{~m}^{2}\right]$ & 30 & 40 & 50 & 60 & 70 & 85 & 100 & 125 & 150 & 175 & 200 \\
\hline Lat. $\mathrm{N}$ impact point $\left[^{\circ}\right]$ & 44.8245 & 44.8287 & 44.8318 & 44.8343 & 44.8364 & 44.8390 & 44.8412 & 44.8441 & 44.8466 & 44.8486 & 44.850 \\
\hline Long. E impact point $\left[^{\circ}\right]$ & 10.9759 & 10.9773 & 10.9789 & 10.9804 & 10.9819 & 10.9841 & 10.9862 & 10.9893 & 10.9921 & 10.9947 & 10.997 \\
\hline$L[\mathrm{~km}, \pm 0.3]$ & 0.4 & 0.7 & 1.0 & 1.2 & 1.5 & 1.8 & 2.0 & 2.4 & 2.7 & 3.0 & 3.3 \\
\hline$X[\mathrm{~km}, \pm 0.4]$ & 2.3 & 1.9 & 1.7 & 1.5 & 1.4 & 1.2 & 1.1 & 1.0 & 0.8 & 0.8 & 0.7 \\
\hline$v_{\text {impact }}\left[\mathrm{m} \mathrm{s}^{-1}\right]$ & 28 & 32 & 36 & 39 & 42 & 47 & 51 & 56 & 62 & 66 & 71 \\
\hline
\end{tabular}

Figure 6 shows the computed strewn-field for the Cavezzo meteorite, together with the terminal part of the luminous atmospheric trajectory projected on the ground (red line), and the location where the two fragments were recovered (purple star). By assuming that a fragmentation occurred, the impact point computed with a purely ablative model is not representative of the real case. Therefore, we computed the expected impact point for fragments with different mass-section ratios, ranging from $D=30$ up to 200 $\mathrm{kg} \mathrm{m}^{-2}$, which is approximately the final value for the mainmass pure ablation (Sect. 3.4). The brown thick line shows the most probable impact point as a function of $D$, while the $\mathrm{red} /$ orange/yellow shaded areas represent the $1 / 2 / 3 \sigma$ uncertainty, respectively, in the transverse direction. The $1 \sigma$ uncertainty in the longitudinal direction can be estimated to be $300 \mathrm{~m}$. Table 4 reports the impact parameters for the sampled $D$ values. The lateral displacement $(X)$ can be as high as $2.3 \mathrm{~km}$ for smaller fragments. The expected impact velocity ranges from 28 to $71 \mathrm{~m} \mathrm{~s}^{-1}$. The position of the recovered fragments lies at the very border of the $1 \sigma$ transverse interval, in a region where recovered fragments are expected to have mass-section ratio values between 30 and $50 \mathrm{~kg} \mathrm{~m}^{-2}$. The $D$ values for the two fragments can be estimated to be $30-70 \mathrm{~kg} \mathrm{~m}^{-2}$ for $\mathrm{F} 1$ and $35-85 \mathrm{~kg} \mathrm{~m}^{-2}$ for $\mathrm{F} 2$, considering that we ignore the orientations of the meteorites during the fall. Therefore, the mass-section ratio for both F1 and F2 is compatible with the predicted values of the dark-flight model. However, since the meteorite very likely fragmented on the ground due to the impact, the $D$ value of the original body remains unknown.

\section{A POSSIBLE PROGENITOR OF THE CAVEZZO METEORITE}

Using the value of $12.8 \pm 0.2 \mathrm{~km} \mathrm{~s}^{-1}$ for the pre-atmospheric velocity, we computed the heliocentric orbit of the meteoroid prior to the impact. The true geocentric speed results to be $5.8 \pm 0.5 \mathrm{~km} \mathrm{~s}^{-1}$. The orbital elements are reported in Tab. 5. The apparent radiant $\left(\alpha_{a}=6.5 \pm 0.2, \delta_{a}=30^{\circ} .6 \pm 0.2\right)$ is located in the Andromeda constellation, while the true radiant $\left(\alpha_{t}=358^{\circ} .4 \pm 0.3, \delta_{t}=24^{\circ} .4 \pm 0.3\right)$ is in Pegasus. The computed heliocentric orbit, shown as the red ellipse (nominal value) and shaded area ( $1 \sigma$ uncertainty) in Fig. 7 , has moderate eccentricity and low inclination on the Ecliptic, with a Tisserand invariant with respect to Jupiter equal to $4.1 \pm 0.2$, thus indicating that the progenitor meteoroid was of asteroidal origin.

To find possible progenitor(s) of the Cavezzo meteorite,
Table 5. Orbital elements (top) and proper elements (bottom) of the Cavezzo meteoroid (left) and of $2013 \mathrm{VC}_{10}$ from NEODyS (right).

\begin{tabular}{lll}
\hline Quantity & Cavezzo & $2013 \mathrm{VC}_{10}$ \\
\hline Epoch & $\mathrm{J} 2000$ & MJD59000 \\
Semi major axis [AU] & $1.82 \pm 0.22$ & 1.56622 \\
Eccentricity & $0.460 \pm 0.063$ & 0.365295 \\
Inclination [ ${ }^{\circ}$ ] & $4.0 \pm 1.6$ & 2.044 \\
Long. of ascending node $\left[^{\circ}\right]$ & $280.52311 \pm 0.00001$ & 224.068 \\
Argument of Perihelion $\left[^{\circ}{ }^{\circ}\right.$ & $179.2 \pm 4.8$ & 240.264 \\
Longitude of Perihelion [ $\left.{ }^{\circ}\right]$ & $99.7 \pm 4.8$ & 104.332 \\
Perihelion passage [JD] & $2458849.6 \pm 0.5$ & 2458808.1 \\
Perihelion distance [AU] & $0.983 \pm 0.001$ & 0.9941 \\
Aphelion distance [AU] & $2.66 \pm 0.41$ & 2.1383 \\
\hline$U$ & $0.216 \pm 0.001$ & 0.1818 \\
$\theta\left[^{\circ}\right]$ & $22.96 \pm 0.30$ & 24.8358 \\
$\phi\left[^{\circ}\right]$ & $175.90 \pm 0.69$ & 171.49 \\
$\lambda_{\oplus}\left[{ }^{\circ}\right]$ & $100.52311 \pm 0.00001$ & 104.986 \\
\hline
\end{tabular}

we followed the procedure described in Carbognani et al. (2020), using the orbital similarity criterion $D_{N}$ introduced by Valsecchi et al. (1999); the NEODyS database ${ }^{10}$ conveniently lists the secular quantities used in $D_{N}$ for all Near-Earth Asteroids (NEAs) for which they are defined (Gronchi \& Milani 2001). We use $D_{N}$ in the form:

$D_{N}=\sqrt{\left(U-U_{c}\right)^{2}+\left(\cos \theta-\cos \theta_{c}\right)^{2}+\Delta \xi^{2}}$,

with:

$$
\begin{aligned}
& \Delta \xi^{2}=\min \left[\Delta \phi_{I}^{2}+\Delta \lambda_{I}^{2}, \Delta \phi_{I I}^{2}+\Delta \lambda_{I I}^{2}\right] \\
& \left\{\begin{array}{l}
\Delta \phi_{I}=2 \sin \frac{\phi-\phi_{c}}{2} \\
\Delta \phi_{I I}=2 \sin \frac{180^{\circ}+\phi-\phi_{c}}{2} \\
\Delta \lambda_{I}=2 \sin \frac{\lambda_{\oplus}-\lambda_{\oplus, c}}{2} \\
\Delta \lambda_{I I}=2 \sin \frac{180^{\circ}+\lambda_{\oplus}-\lambda_{\oplus, c}}{2} .
\end{array}\right.
\end{aligned}
$$

In the above expressions, $U, \theta, \phi, \lambda_{\oplus}$ refer to the NEA, and are taken from NEODyS, while $U_{c}, \theta_{c}, \phi_{c}, \lambda_{\oplus, c}$ are those of the Cavezzo meteorite (Tab. 5). Details on the definition of the variables and on $D_{N}$ are given in Valsecchi et al. (1999). We looked for NEAs for which $D_{N} \leq 0.15$. The search resulted

10 NEODyS-2 database - https://newton. spacedys.com/ neodys $2 /$ propneo/e 
in only one candidate, $2013 \mathrm{VC}_{10}$, for which proper elements are given in the last column of Tab. 5; for the pair Cavezzo$2013 \mathrm{VC}_{10}, D_{N}=0.115$. The nominal orbit of $2013 \mathrm{VC}_{10}$, projected onto the ecliptic plane, is shown in Fig. 7 (blue ellipse). There is a reasonable similarity between the two orbits, which is more evident if one considers the secular quantities that enter the computation of $D_{N}$. On the other hand, the pair Cavezzo- $2013 \mathrm{VC}_{10}$ is rather isolated in the 4-dimensional space $U, \theta, \phi, \lambda_{\oplus}$; this isolation is recognisable even in the 2-dimensional space constituted by the ecliptical radiant coordinates. Figure 8 shows the radiants of the pair Cavezzo-2013 $\mathrm{VC}_{10}$, as well as the radiants of the simulated impactors of Chesley \& Spahr (2004), and of the 20 real impactors listed in Granvik \& Brown (2018). As discussed in the Appendix of Farnocchia et al. (2012), the radiant distribution simply reflects the values of the semi-major axis, eccentricity and inclination of those NEAs whose orbits actually can cross that of the Earth. As a result, NEA impactor radiants are not uniformly distributed in a plot like Fig. 8a, but present concentrations and regions of low density that are even more evident in Fig. $8 \mathrm{~b}$. It is in one of the low-density regions that the pair Cavezzo- $2013 \mathrm{VC}_{10}$ is located, lending some additional credibility to the possible association.

\section{CONCLUSIONS}

After less than three years of operations, the PRISMA network, partner of FRIPON, has achieved one of its major objectives, i.e. the recovery of the first Italian meteorite by computation of a precise strewn-field through the analysis of its observational data. Two meteorite fragments, fallen near Cavezzo (Modena) on New Year's Day 2020, weighing $3.1 \mathrm{~g}$ and $52.2 \mathrm{~g}$, were recovered three days after the fall as a result of a dedicated field search and thanks to the involvement of local people. They were found at a distance of $400 \mathrm{~m}$ from the nominal computed position, very close to the $1 \sigma$ uncertainty value. These fragments were immediately recognised as freshly fallen meteorites, a fact that has been confirmed by the unquestionable presence of short-lived cosmogenic radioisotopes (such as ${ }^{48} \mathrm{~V}$, half-life of $15.97 \mathrm{~d}$ ) measured with a very sensitive $\gamma$-ray detector at the INAF Monte dei Cappuccini Laboratory in Torino. The analyses carried out at the Department of Earth Sciences of the Firenze University highlighted strong differences between the two specimens and led the Nomenclature Committee of the Meteoritical Society to approve the classification proposal of anomalous L5 chondrite.

The computed orbital parameters and the value of the Tisserand invariant $\left(T_{J}=4.1 \pm 0.2\right)$ are typical of a NEA with an aphelion located in the inner part of the main belt. The orbital elements, compared with the ones of known NEAs from the NEODyS database, show that only one object among those, namely $2013 \mathrm{VC}_{10}$, is compatible with the Cavezzo meteoroid. Moreover, the radiants of both objects are located in a low-density region of NEA impactors, thus lending additional credibility to the association.

The associated fireball trajectory, observed by many eyewitnesses, was characterised by an entry velocity of 12.2 $\pm 0.2 \mathrm{~km} \mathrm{~s}^{-1}$ and by a high inclination angle of $68^{\circ} .4 \pm 0.3$.

The luminous path started at a height of $75.9 \pm 0.2 \mathrm{~km}$ and reached $21.5 \pm 0.1 \mathrm{~km}$, after travelling approximately $59 \mathrm{~km}$ in $5.6 \mathrm{~s}$. The absolute magnitude reached a minimum of -9.5 at $32.6 \mathrm{~km}$ of altitude, where a bright flash was seen, very likely indicating a fragmentation and followed by a second flash reaching -8.5. In the brightest part of the trajectory, the mean absolute magnitude was around -7.5. By assuming a purely ablative regime, a spherical form of the meteoroid, and given the measured meteorite bulk density of $3.322 \mathrm{~g} \mathrm{~cm}^{-3}$, the estimated residual mass is $1.5 \pm 0.4 \mathrm{~kg}$.

The pre-atmospheric mass and velocity of $3.5 \pm 0.8 \mathrm{~kg}$ and $12.8 \pm 0.2 \mathrm{~km} \mathrm{~s}^{-1}$, respectively, leading to a total impact energy of less than $0.07 \mathrm{~T}$ TNT, together with the brightest absolute magnitude reached, are the lowest among those estimated for the 35 meteorites with "pedigree" recovered so far, as listed in Tab. 1. Currently, this recovery ean be considered to date the most challenging in terms of size and magnitude of the associated event, proving the efficiency of the network and of our reduction pipeline even in such demanding conditions.

\section{ACKNOWLEDGEMENTS}

PRISMA is the Italian network for systematic surveillance of meteors and atmosphere. It is a collaboration initiated and coordinated by the Italian National Institute for Astrophysics (INAF) that counts members among research institutes, universities, associations and schools. The complete list of PRISMA members is available here: http://www.prisma.inaf.it. PRISMA was funded by 2016/0476 and 2019/0672 Research and Education grants from Fondazione Cassa di Risparmio di Torino and by a 2016 grant from Fondazione Agostino De Mari (Savona). PRISMA data are hosted by the INAF research e-infrastructure project IA2 (Italian Center for Astronomical Archives).

FRIPON was funded by the ANR grant N.13-BS050009-03, carried by the Paris Observatory, MusÃl'um National dâĂŹHistoire Naturelle, Paris-Saclay University and Institut PythÃl'as (LAM-CEREGE). FRIPON data are hosted and processed at Institut PythÃl'as SIP (Service Informatique Pyth $\tilde{A}$ l'as), and a mirror is hosted at IMCCE (Institut de MÃ̃l'canique CÃl'leste et de Calcul des ÂL'ph Ãl'mÂll'rides / Paris Observatory) with the help of IDOC (Integrated Data and Operation Center), supported by CNRS and CNES.

The PRISMA collaboration is grateful to Mr. Davide Gaddi, who recovered the meteorite fragments, allowed for the analysis of the samples and eventually decided to donate them to INAF.

The authors are very grateful to Leonard KornoÅa for the useful comments that greatly improved the manuscript and to Rebecca O'Brien for the precious work of language revision.

Background map data for Fig. 6 copyrighted OpenStreetMap contributors and available from https://www.openstreetmap.org, distributed under the Open Data Commons Open Database License (https://opendatacommons.org/licenses/odbl/). 


\section{DATA AVAILABILITY}

PRISMA data underlying this article will be shared on reasonable request to the corresponding author.

\section{REFERENCES}

Audureau Y., et al., 2014, in Proceedings of the 33th International Meteor Conference, Giron, France, 18 - 21 September 2014. pp 39-41

Barghini D., Gardiol D., Carbognani A., 2019a, in Proceedings of the 37th International Meteor Conference Pezinok-Modra, Slovakia, 30 August - 2 September 2018. pp 41-45

Barghini D., Gardiol D., Carbognani A., Mancuso S., 2019b, A\&A, 626, A105

Bischoff A., et al., 2011, Meteorit. Planet. Sci., 46, 793

Bischoff A., Dyl K. A., Horstmann M., Ziegler K., Wimmer K., Young E. D., 2013, Meteorit. Planet. Sci., 48, 628

Bischoff A., et al., 2017, Meteorit. Planet. Sci., 52, 1683

Bischoff A., et al., 2019, Geochemistry / Chem. Erde, 79, 125525

Bland P. A., et al., 2009, Science, 325, 1525

Bland P. A., et al., 2016, in 79th Annual Meeting of the Meteoritical Society. p. 6265

Borovička J., 1990, Bull. Astron. Inst. Czechoslov., 41, 391

Borovička J., Kalenda P., 2003, Meteorit. Planet. Sci., 38, 1023

Borovička J., Spurný P., Keclikova J., 1995, A\&AS, 112, 173

Borovička J., Popova O. P., Nemtchinov I. V., Spurný P., Ceplecha Z., 1998, A\&A, 334, 713

Borovička J., Spurný P., Kalenda P., Tagliaferri E., 2003a, Meteorit. Planet. Sci., 38, 975

Borovička J., et al., 2003b, Meteorit. Planet. Sci., 38, 1005

Borovička J., Charvát Z., 2009, A\&A, 507, 1015

Borovička J., et al., 2013a, Meteorit. Planet. Sci., 48, 1757

Borovička J., Spurný P., Brown P., Wiegert P., Kalenda P., Clark D., Shrbený L., 2013b, Nature, 503, 235

Borovička J., et al., 2015, Meteorit. Planet. Sci., 50, 1244

Borovička J., Popova O., Spurný P., 2019, Meteorit. Planet. Sci., 54,1024

Bouvier A., Gattacceca J., Agee C., Grossman J., Metzler K. 2017, Meteorit. Planet. Sci., 52, 2284

Brown P., Ceplecha Z., Hawkes R. L., Wetherill G., Beech M., Mossman K., 1994, Nature, 367, 624

Brown P. G., et al., 2000, Science, 290, 320

Brown P. G., Revelle D. O., Tagliaferri E., Hildebrand A. R., 2002, Meteorit. Planet. Sci., 37, 661

Brown P., Pack D., Edwards W. N., Revelle D. O., Yoo B. B., Spalding R. E., Tagliaferri E., 2004, Meteorit. Planet. Sci., 39,1781

Brown P., et al., 2011, Meteorit. Planet. Sci., 46, 339

Brown P. G., et al., 2013, Nature, 503, 238

Brown P. G., et al., 2019, Meteorit. Planet. Sci., 54, 2027

Carbognani A., et al., 2020, Eur. Phys. J. Plus, 135, 255

Ceplecha Z., 1961, Bull. Astron. Inst. Czechoslov., 12, 21

Ceplecha Z., 1987, Bull. Astron. Inst. Czechoslov., 38, 222

Ceplecha Z., 1996, A\&A, 311, 329

Ceplecha Z., Revelle D. O., 2005, Meteorit. Planet. Sci., 40, 35

Chesley S. R., Spahr T. B., 2004, in Mitigation of Hazardous Comets and Asteroids. p. 22

Clark D. L., Wiegert P. A., 2011, Meteorit. Planet. Sci., 46, 1217

Colas F., et al., 2014, in Proceedings of the 33th International Meteor Conference, Giron, France, 18-21 September 2014. pp $18-21$

Colas F., et al., 2020, A\&A (submitted)

Colombetti P., Taricco C., Bhandari N., Sinha N., Di Martino M., Cora A., Vivaldo G., 2013, Nucl. Instrum. Methods Phys. Res. A, 718, 140

Devillepoix H. A. R., et al., 2018, Meteorit. Planet. Sci., 53, 2212
Devillepoix H. A. R., et al., 2019, MNRAS, 483, 5166

Dyl K. A., et al., 2016, Meteorit. Planet. Sci., 51, 596

Farnocchia D., Bernardi F., Valsecchi G. B., 2012, Icarus, 219, 41

Ferus M., et al., 2020, Icarus, 341, 113670

Foschini L., 1999, A\&A, 342, L1

Gardiol D., Cellino A., Di Martino M., 2016, in Proceedings of the 35th International Meteor Conference Egmond, the Netherlands, 2-5 June 2016. pp 76-79

Gardiol D., et al., 2019, in Proceedings of the 37th International Meteor Conference Pezinok-Modra, Slovakia, 30 August - 2 September 2018. pp 81-86

Gattacceca J., Bouvier A., Grossman J., Metzler K., Uehara M., 2019, Meteorit. Planet. Sci., 54, 469

Gattacceca J., MCcubbin F. M., Bouvier A., Grossman J., 2020, Meteorit. Planet. Sci., 55, 460

Gounelle M., Spurný P., Bland P. A., 2006, Meteorit. Planet. Sci., 41, 135

Granvik M., Brown P., 2018, Icarus, 311, 271

Gronchi G. F., Milani A., 2001, Icarus, 152, 58

Haack H., et al., 2012, Meteorit. Planet. Sci., 47, 30

Haack H., et al., 2019, Meteorit. Planet. Sci, 54, 1853

Halliday I., Griffin A. A., Blackwell A. T., 1981, Meteoritics, 16,153

Hildebrand A. R., McCausland P. J.A., Brown P. G., Longstaffe F. J., Russell S. D. J., Tagliaferri E., Wacker J. F., Mazur M. J., 2006, Meteorit. Planet. Sci., 41, 407

Hildebrand A. R., et al., 2009, in Lunar and Planetary Science Conference. Lunar and Planetary Science Conference. p. 2505

Hunter J. D., 2007, Comput Sci. Eng., 9, 90

Jeanne S., et al., 2019, A\&A, 627, A78

Jenniskens P., et al., 2009, Nature, 458, 485

Jenniskens P., et al., 2012, Science, 338, 1583

Jenniskens P., et al., 2014, Meteorit. Planet. Sci., 49, 1388

Jenniskens P., et al., 2019, Meteorit. Planet. Sci., 54, 699

Jenniskens P., et al., 2020, Meteorit. Planet. Sci., 55, 535

Kalenichenko V. V., 2006, A\&A, 448, 1185

Knapic C., De Marco M., Smareglia R., Molinaro M., 2014, in Astronomical Data Analysis Software and Systems XXIII. p. 131

Kohout T. ¡., et al., 2017, Meteorit. Planet. Sci., 52, 1525

Kruijer T. S., Kleine T., Borg L. E., 2020, Nat. Astron., 4, 32

Llorca J., et al., 2005, Meteorit. Planet. Sci., 40, 795

McCrosky R. E., Posen A., Schwartz G., Shao C. Y., 1971, J. Geophys. Res., 76, 4090

Milley E. P., Hildebrand A. R., Brown P. G., Noble M., Sarty G., Ling A., Maillet L. A., 2010, in GeoCanada 2010.

Palotai C., Sankar R., Free D. L., Howell J. A., Botella E., Batcheldor D., 2019, MNRAS, 487, 2307

Popova O., Borovička J., Hartmann W. K., Spurný P., Gnos E., Nemtchinov I., Trigo-Rodríguez J. M., 2011, Meteorit. Planet. Sci., 46, 1525

Popova O. P., et al., 2013, Science, 342, 1069

Pratesi G., et al., 2020, Meteorit. Planet. Sci. (submitted)

Revelle D. O., Brown P. G., Spurný P., 2004, Meteorit. and Planet. Sci., 39, 1605

Sansom E. K., et al., 2020, arXiv e-prints, p. arXiv:2006.07151

Shaddad M. H., et al., 2010, Meteorit. Planet. Sci., 45, 1557

Simon S. B., Grossman L., Clayton R. N., Mayeda T. K., Schwade J. R., Sipiera P. P., Wacker J. F., Wadhwa M., 2004, Meteorit. Planet. Sci., 39, 625

Spurný P., 1994, Planet. Space Sci., 42, 157

Spurný P., Heinlein D., Oberst J., 2002, in Warmbein B., ed., ESA Special Publication Vol. 500, Asteroids, Comets, and Meteors: ACM 2002. pp 137-140

Spurný P., Oberst J., Heinlein D., 2003, Nature, 423, 151

Spurný P., Borovička J., Kac J., Kalenda P., Atanackov J., Kladnik G., Heinlein D., Grau T., 2010, Meteorit. Planet. Sci., 45, 1392 
Spurný P., Bland P. A., Shrbený L., Towner M. C., Borovička J., Bevan A. W. R., Vaughan D., 2011, Meteorit. Planet. Sci. Suppl., 74, 5101

Spurný P., et al., 2012, Meteorit. Planet. Sci., 47, 163

Spurný P., Haloda J., Borovička J., Shrbený L., Halodová P., 2014, A\&A, 570, A39

Spurný P., Borovička J., Haloda J., Shrbeny L., Heinlein D., 2016, in 79th Annual Meeting of the Meteoritical Society. p. 6221

Spurný P., Borovička J., Baumgarten G., Haack H., Heinlein D., Sørensen A. N., 2017a, Planet. Space Sci., 143, 192

Spurný P., Borovička J., Mucke H., Svoreň J., 2017b, A\&A, 605, A68

Spurný P., Bland P. A., Borovička J., Towner M. C., Shrbeny L., Bevan A. W. R., Vaughan D., 2019, in Meteoroids 2019, Bratislava, Slovakia, 17-21 June 2019.. p. 6369

Spurný P., Borovička J., Shrbený L. i., 2020, Meteorit. Planet. Sci., 55, 376

Steinacker R., Mayer D., Steiner A., 2011, Mon. Weather Rev., 139, 3974

Taricco C., Bhandari N., Cane D., Colombetti P., Verma N., 2006, J. Geophys. Res., 111, A08102

Tavolato C., Isaksen L., 2015, Q. J. R. Meteorol. Soc., 141, 1514

Tóth J., et al., 2015, Meteorit. Planet. Sci., 50, 853

Trigo-Rodríguez J. M., Borovička J., Spurný P., Ortiz J. L., Docobo J. A., Castro-Tirado A. J., Llorca J., 2006, Meteorit. Planet. Sci., 41, 505

Trigo-Rodríguez J. M., et al., 2015, MNRAS, 449, 2119

Unsalan O., et al., 2019, Meteorit. Planet. Sci., 54, 953

Valsecchi G. B., Jopek T. J., Froeschle C., 1999, MNRAS, 304, 743

Vida D., Brown P. G., Campbell-Brown M., 2018, MNRAS, 479,4307

Welten K. C., Meier M. M. M., Caffee M. W., Nishiizumi K., Wieler R., Jenniskens P., Shaddad M. H., 2010, Meteorit. Planet. Sci., 45, 1728

Wilson G., McCausland P., 2012, Can. J Earth Sci., 50, 4

\section{AFFILIATIONS}

${ }^{1}$ INAF - Osservatorio Astrofisico di Torino, Via Osservatorio 20, 10025 Pino Torinese, TO, Italy

${ }^{2}$ Universit $\tilde{A} \breve{a}$ degli Studi di Torino - Dipartimento di Fisica, Via Pietro Giuria 1, 10125 Torino, TO, Italy

${ }^{3}$ INAF - Osservatorio di Astrofisica e Scienza dello Spazio, Via Piero Gobetti 93/3, 40129 Bologna, BO, Italy

${ }^{4}$ INAF - Osservatorio Astronomico dâĂŹAbruzzo, Via Mentore Maggini SNC, LocalitÃă Collurania, 64100 Teramo, TE, Italy

${ }^{5}$ INAF - Osservatorio Astronomico di Trieste, Via Giambattista Tiepolo 11, 10134 Trieste, TS, Italy

${ }^{6}$ UniversitÃ $\breve{a}$ degli Studi di Firenze - Dipartimento di Scienze della Terra, Via Giorgio La Pira, 4, 50121 Firenze, FI, Italy

${ }^{7}$ INAF - Istituto di Astrofisica e Planetologia Spaziali, Via del Fosso del Cavaliere 100, 00133 Roma, RM, Italy

${ }^{8}$ Osservatorio Astronomico del Righi, Via Mura delle Chiappe 44R, 16136 Genova, GE, Italy

${ }^{9}$ Meteo Expert, Via Giovanni Frova, 34, 20092 Cinisello Balsamo, MI, Italy

${ }^{10}$ IFAC - CNR, Via Madonna del Piano 10, 50019 Sesto Fiorentino, FI, Italy

${ }^{11}$ IMCCE, Observatoire de Paris, PSL Research University, CNRS UMR 8028, Sorbonne UniversitÃl', UniversitÃl' de Lille, 77 av. Denfert-Rochereau, 75014 Paris, France
${ }^{12}$ FRIPON (Fireball Recovery and InterPlanetary Observation) and Vigie-Ciel Team, France

${ }^{13}$ Institut de MinÃl'ralogie, Physique des MatÃl'riaux et Cosmochimie (IMPMC), MusÃl'um National dâĂŹHistoire Naturelle, CNRS UMR 7590, Sorbonne UniversitÃl', 75005 Paris, France

${ }^{14}$ GEOPS - GÃl'osciences, CNRS, UniversitÃl' ParisSaclay, 91405 Orsay, France

${ }^{15}$ Service Informatique PythÃl'as (SIP) CNRS - OSU Institut Pyth $\tilde{A}$ l'as - UMS 3470, Marseille, France

${ }^{16}$ Aix Marseille UniversitÃl', CNRS, IRD, Coll France, INRA, CEREGE, Aix-enProvence, France

${ }^{17}$ International Meteor Organization

${ }^{18}$ Aix Marseille Universit $\tilde{A} l$ ', CNRS, CNES, LAM, Marseille, France

${ }^{19} \mathrm{La}$ Torre del Sole, Via Caduti sul Lavoro 2, 24030 Brembate di Sopra, BG, Italy

${ }^{20}$ Associazione Astrofili Bisalta, Via Gino Eula 23, 12013

Chiusa di Pesio, CN, Italy

${ }^{21}$ Associazione Sky Sentinel, Via Giovanni Leone 36, 81020 San Nicola la Strada, CE, Italy

${ }^{22}$ Meteoriti Italia APS, Via Fusina 6, 32032 Feltre, BL, Italy

${ }^{23}$ GAMP - Osservatorio Astronomico Montagna Pistoiese, 51028 San Marcello Piteglio, PT, Italy

${ }^{24}$ Gruppo Astrofili Antares, Via Garibaldi 12, 48033 Cotignola, $R A$, Italy

${ }^{25}$ INAF - Osservatorio Astronomico di Brera, Via Brera 28, 20121 Milano, MI, Italy

${ }^{26}$ Associazione Astronomica del Rubicone, Via Palmiro Togliatti 5, 47039 Savignano sul Rubicone, FC, Italy

${ }^{27}$ INAF - Osservatorio Astrofisico di Catania, Via Santa Sofia 78, 95123 Catania, CT, Italy

${ }^{28}$ SpaceDyS, Via Mario Giuntini 63, 56023 Navacchio di Cascina, PI, Italy

${ }^{29}$ Universit $\tilde{A} \breve{a}$ di Firenze - Osservatorio Polifunzionale del Chianti, Strada Provinciale Castellina in Chianti, 50021 Barberino Val D'Elsa, FI, Italy

${ }^{30}$ Associazione Astrofili Urania, LocalitÃ ă Bric del Colletto 1, 10062 Luserna San Giovanni, TO, Italy

${ }^{31}$ INAF - Osservatorio Astronomico di Capodimonte, Salita Moiariello 16, 80131 Napoli, NA, Italy

${ }^{32}$ Associazione Astrofili Tethys - Planetario e Osservatorio Astronomico di Ca' del Monte, Localit $\tilde{a} \breve{a} \mathrm{Ca}$ ' del Monte, 27050 Cecima, PV, Italy

${ }^{33}$ INFN - Sezione di Torino, Via Pietro Giuria 1, 10125 Torino, TO, Italy

${ }^{34}$ Associazione Culturale Googol, Via Filippo Brunelleschi 21, 43100 Parma, PR, Italy

${ }^{35}$ INAF - Osservatorio Astronomico di Padova, Vicolo dell'Osservatorio 5, 35122 Padova, PD, Italy

${ }^{36}$ Fondazione GAL Hassin - Centro Internazionale per le Scienze Astronomiche, Via della Fontana Mitri, 90010 Isnello, PA, Italy

${ }^{37}$ Planetarium Pythagoras, Via Margherita Hack, 89125 Reggio Calabria, $R C$, Italy

${ }^{38}$ Universit $\tilde{a} \breve{a}$ del Salento - Dipartimento di Matematica e

Fisica, Via Per Arnesano, 73100 Lecce, LE, Italy

${ }^{39}$ Fondazione Museo Civico di Rovereto - Osservatorio Astronomico di Monte Zugna, LocalitÃ $\breve{a}$ Zugna, 38068 Rovereto, TN, Italy

${ }^{40}$ Liceo Statale 'Arturo Issel', Via Fiume 42, 17024 Finale 
Ligure, SV, Italy

${ }^{41}$ Gruppo Astrofili Monti Lepini - Osservatorio Astronomico e Planetario di Gorga, 00030 Gorga, RM, Italy

${ }^{42}$ UniversitÃă di Camerino - Scuola di Scienze e Tecnologie, sezione Geologia, via Gentile III da Varano, 62032 Camerino, $M C$, Italy

${ }^{43}$ INAF - Istituto di Radioastronomia, Via Piero Gobetti 101, 40129 Bologna, BO, Italy

${ }^{44}$ Gruppo Astrofili Montelupo Fiorentino, Piazza Vittorio Veneto 10, 50056 Montelupo Fiorentino, FI, Italy

${ }^{45}$ Universit $\tilde{a} \breve{a}$ di Padova - Dipartimento di Fisica e Astronomia, Vicolo dell'Osservatorio 3, 35122 Padova, PD, Italy

${ }^{46}$ Osservatorio Astrofisico R.P. Feynman, 73034 Gagliano del Capo, LE, Italy

${ }^{47}$ Osservatorio Astronomico Sirio, Piazzale Anelli, 70013 Castellana Grotte, BA, Italy

${ }^{48}$ Osservatorio Astronomico di Sormano, Localit $\tilde{A} \breve{a}$ Colma di, 22030 Sormano, CO, Italy

${ }^{49}$ INAF - Osservatorio Astrofisico di Arcetri, Largo Enrico Fermi 5, 50125 Firenze, FI, Italy

${ }^{50}$ Associazione Astrofili di Piombino - Osservatorio Astronomico di Punta Falcone, Punta Falcone, 57025 Piombino, LI, Italy

${ }^{51}$ UniversitÃă degli Studi di Firenze - Museo di Storia Naturale, Sistema Museale di Ateneo, Via Giorgio La Pira, 4, 50121 Firenze, FI, Italy

${ }^{52}$ INAF - Osservatorio Astronomico di Cagliari, Via della Scienza 5, 09047 Cuccuru Angius, Selargius, CA, Italy

${ }^{53}$ CIRA - Centro Italiano Ricerche Aerospaziali, Via Maiorise SNC, 81043 Capua, CE, Italy

${ }^{54}$ Astrobioparco Oasi di Felizzano, Strada Fubine 79, 15023 Felizzano, AL, Italy

${ }^{55}$ Associazione Ravennate Astrofili Rheyta, Viale Santi Baldini 4/a, 48121, Ravenna, RA, Italy

${ }^{56}$ Universit $\tilde{A} \breve{a}$ degli Studi di Firenze - Dipartimento di Fisica e Astronomia, Via Sansone 1, 50019 Sesto Fiorentino, FI, Italy

${ }^{57}$ IIS 'E.Fermi' di Montesarchio, Via Vitulanese, 82016 Montesarchio, BN, Italy

${ }^{58}$ Liceo Scientifico Statale 'G.B. Quadri', Viale GiosuAi Carducci 17, 36100 Vicenza, VI, Italy

${ }^{59}$ Universit $\tilde{A} \breve{a}$ degli Studi di Trento - Dipartimento di Ingegneria Civile, Ambientale e Meccanica, Via Mesiano 77, 38123 Trento, TN, Italy

${ }^{60}$ Liceo Scientifico A. Pacinotti, Via XV Giugno SNC, 19123 La Spezia, SP, Italy

${ }^{61}$ UniversitÃă CẩĂŹFoscari di Venezia, Dipartimento di Scienze Ambientali, Informatica e Statistica, Via Torino 155, 30172 Mestre Venezia, VE, Italy

${ }^{62}$ Museo del Cielo e della Terra, Vicolo Baciadonne 1, 40017 San Giovanni in Persiceto, BO, Italy

${ }^{63}$ Associazione Astrofili Paolo Maffei, Strada Cerruti 39, 06131 San Marco, Perugia, PG, Italy

${ }^{64}$ Universit $\tilde{a} \breve{a}$ del Piemonte Orientale - Dipartimento di Scienze e Innovazione Tecnologica, Viale Teresa Michelin 11,15121 Alessandria, AL, Italy

65 Osservatorio Astronomico Giuseppe Piazzi, LocalitÃă San Bernardo, 23026 Ponte in Valtellina, SO, Italy

${ }^{66}$ Liceo Scientifico Statale P. Paleocapa, Via Alcide De Gasperi 19, 45100 Rovigo, RO, Italy
${ }^{67}$ Osservatorio Astronomico Bobhouse, Via Giuseppe Tomasi P.pe di Lampedusa 9, 90147 Palermo, PA, Italy

This paper has been typeset from a $\mathrm{T}_{\mathrm{E}} \mathrm{X} / \mathrm{LAT}_{\mathrm{E}} \mathrm{X}$ file prepared by the author. 


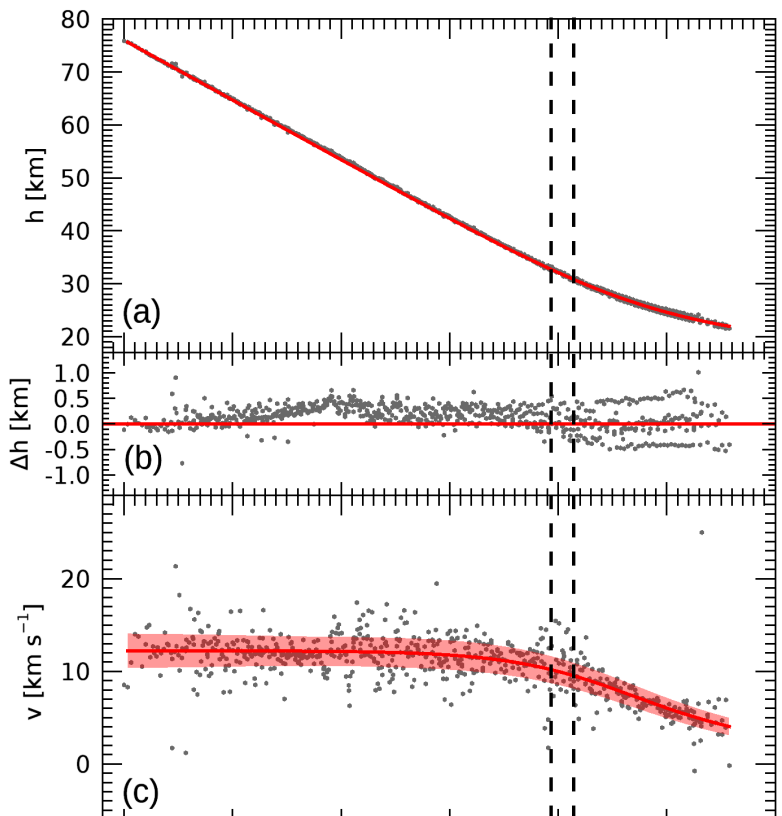

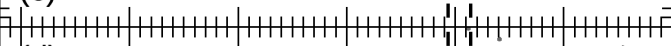

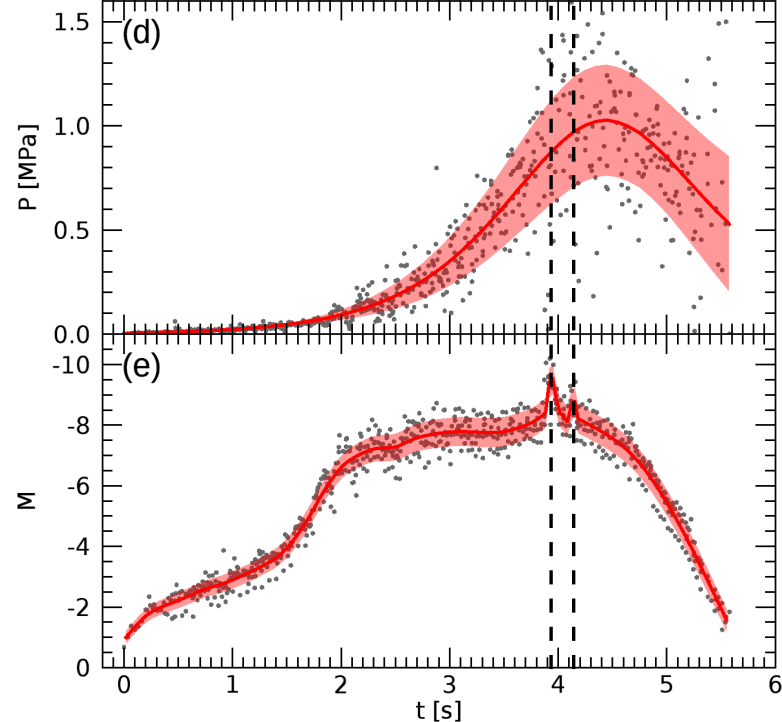

Figure 4. Results of trajectory computation and dynamical model for the IT20200101 fireball. (a) Vertical projection of the atmospheric trajectory; (b) vertical residuals of the atmospheric trajectory; (c) fireball velocity with respect to ground; (d) aerodynamic pressure (Eq. 1); (e) absolute magnitude (at $100 \mathrm{~km}$, zenith of the observer). The $x$-axis reports the time elapsed from the beginning of the visible flight captured by the eight cameras. The two vertical dashed lines indicate the times at which the two flares occurred, $3.95 \mathrm{~s}$ and $4.15 \mathrm{~s}$ respectively. In every panel, grey points plot measured or computed values for the single stations, whereas the red line plots the nominal fit values (a-c) or a smoothed version of grey points $(\mathrm{d}, \mathrm{e})$. Red shaded area encloses $1 \sigma$ uncertainty.

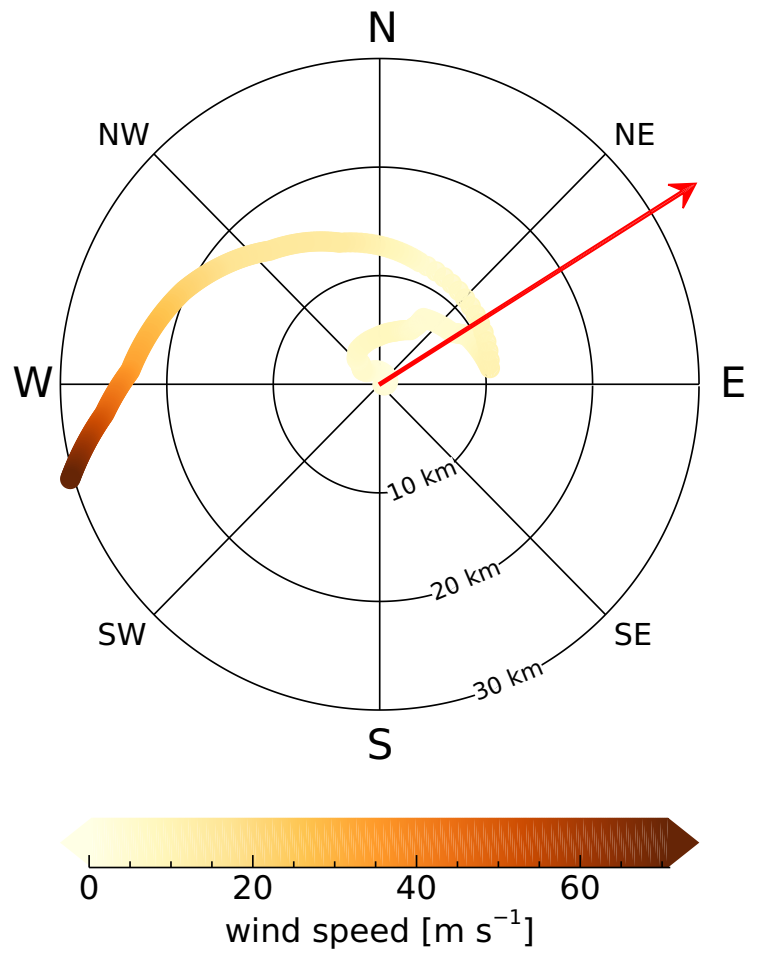

Figure 5. Wind vertical profile at 18 UTC in the Cavezzo area used for the strewn-field computation. The red arrow shows the fireball motion direction on the ground. 


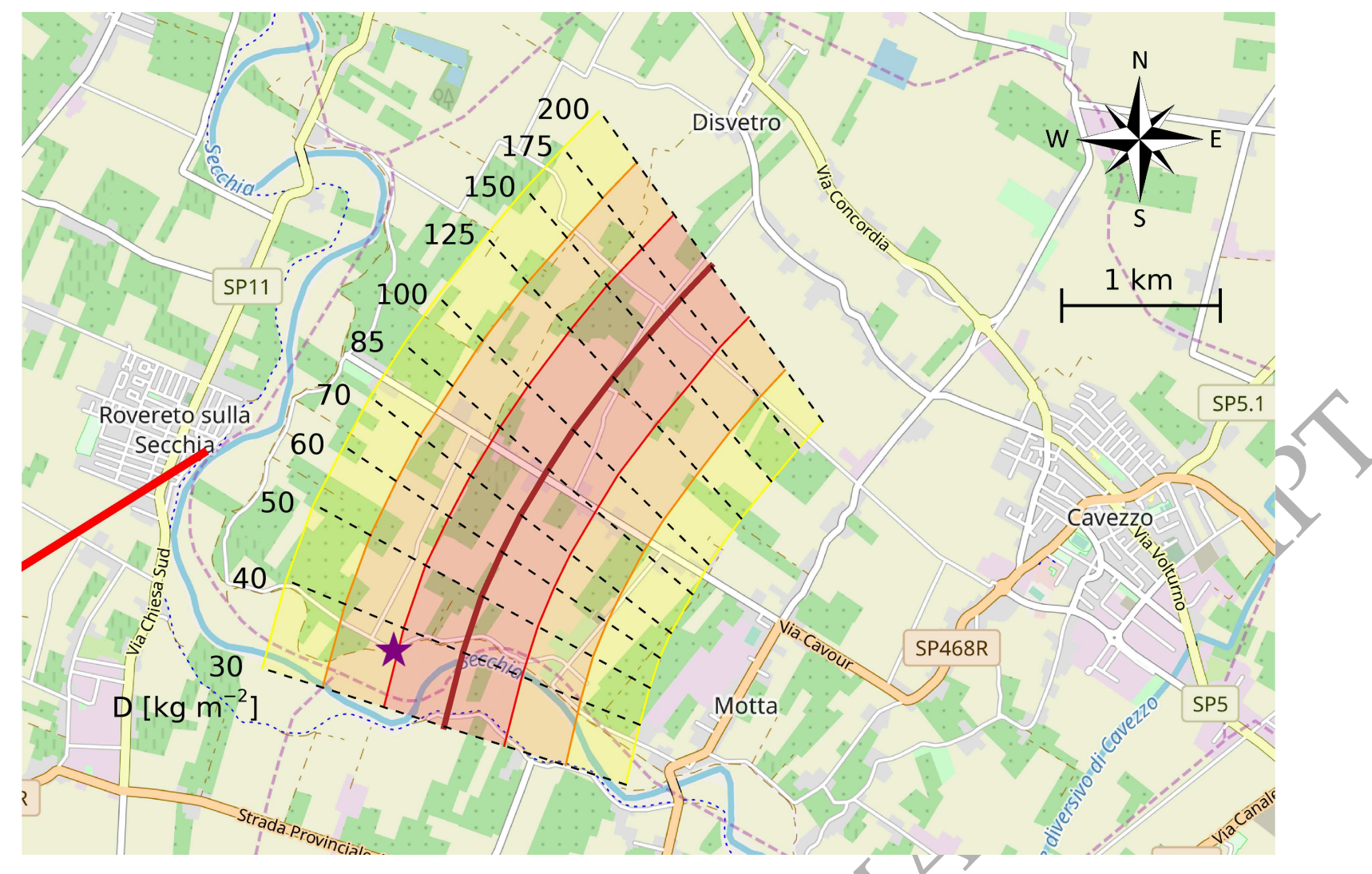

Figure 6. Strewn-field for the Cavezzo meteorite fragments, as a function of different mass-section ratio values $(D$, dashed black lines) from 30 up to $200 \mathrm{~kg} \mathrm{~m}^{-2}$. The brown thick line shows the nominal impact point and the shaded areas enclose $1 \sigma$ (red), $2 \sigma$ (orange) and $3 \sigma$ (yellow) uncertainties in the transverse direction. The purple star shows where the two Cavezzo fragments F1 and F2 were recovered, and the thick red line plots the terminal part of the bright flight trajectory, projected on the ground. Background map data copyrighted OpenStreetMap contributors and available from https://www.openstreetmap.org. 


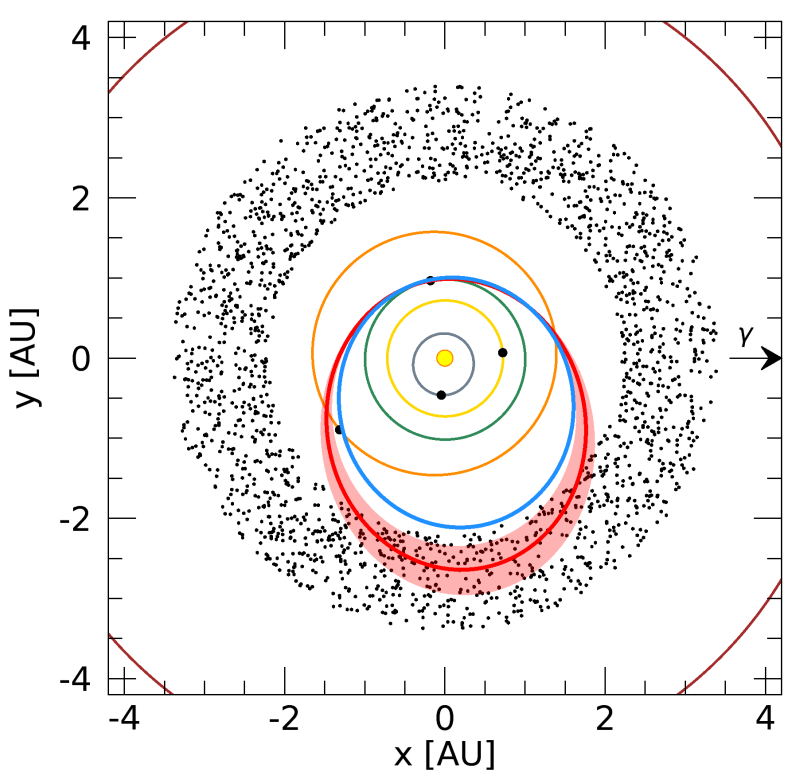

Figure 7. The reconstructed heliocentric orbit for the progenitor meteoroid of the Cavezzo meteorite (red ellipse) as seen from the ecliptic north pole and projected onto the ecliptic plane, together with the $1 \sigma$ uncertainty band (shaded red area). The blue ellipse plots the $2013 \mathrm{VC}_{10}$ orbit (for which orbital elements are provided by the NEODyS database). Remaining ellipses plot Solar System planets' orbits up to Jupiter, and the black dots indicates their position along the orbit at the time of the IT20200101 fireball. The black small dots symbolically represent the asteroid Main Belt.
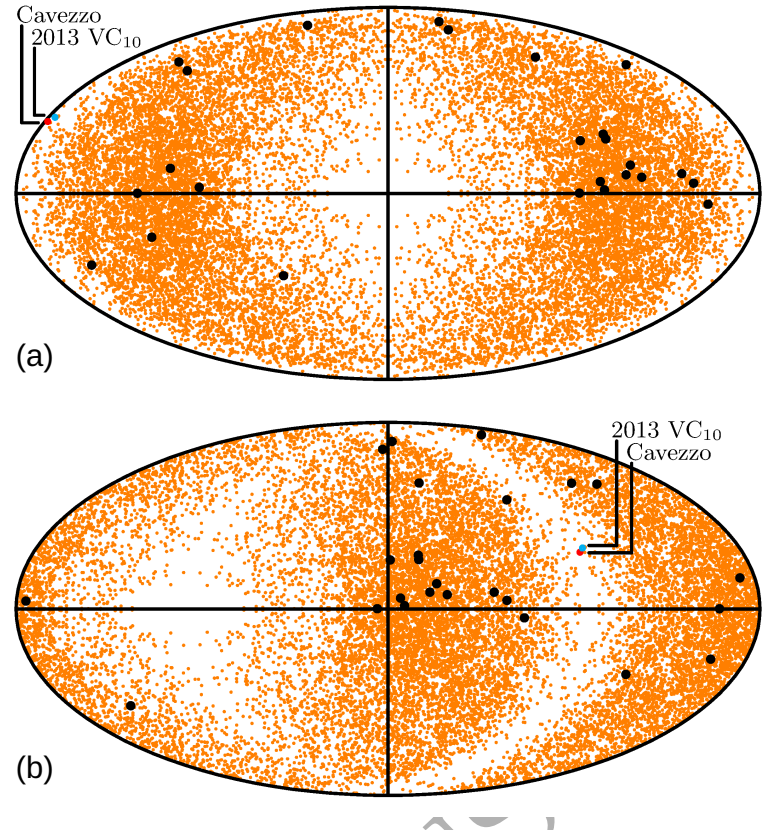

Figure 8. The radiants of the Cavezzo meteoroid (red dot) and of $2013 \mathrm{VC}_{10}$ (cyan dot) in an equal area projection of the sky centred on the apex of the Earth motion (a) and on the opposition (b); the angular coordinates are ecliptic longitude minus the longitude of the Sun, and ecliptic latitude. The orange dots are the radiants of the simulated impactors of Chesley \& Spahr (2004), while the black dots are the radiants of the 20 meteorites listed in Granvik \& Brown (2018). 